\title{
Coaching Knowledge and Noticing in Youth Sports: Challenging the Assumption of Expertise
}

Philip James Liversedge

Follow this and additional works at: https://researchrepository.wvu.edu/etd

\section{Recommended Citation}

Liversedge, Philip James, "Coaching Knowledge and Noticing in Youth Sports: Challenging the Assumption of Expertise" (2016). Graduate Theses, Dissertations, and Problem Reports. 6105.

https://researchrepository.wvu.edu/etd/6105

This Dissertation is protected by copyright and/or related rights. It has been brought to you by the The Research Repository @ WVU with permission from the rights-holder(s). You are free to use this Dissertation in any way that is permitted by the copyright and related rights legislation that applies to your use. For other uses you must obtain permission from the rights-holder(s) directly, unless additional rights are indicated by a Creative Commons license in the record and/ or on the work itself. This Dissertation has been accepted for inclusion in WVU Graduate Theses, Dissertations, and Problem Reports collection by an authorized administrator of The Research Repository @ WVU.

For more information, please contact researchrepository@mail.wvu.edu. 
Coaching Knowledge and Noticing in Youth Sports: Challenging the Assumption of Expertise

\title{
Philip James Liversedge
}

\author{
Dissertation submitted to the College of Physical Activity and Sport Sciences \\ at West Virginia University
}

in partial fulfillment of the requirements for the degree of

Doctor of Philosophy in

Kinesiology with an emphasis in Coaching and Teaching Studies

\author{
Robert Wiegand, Ed.D., Chair \\ Malayna Bernstein, Ph.D. \\ Sean Bulger, Ed.D. \\ Damien Clement, Ph.D. \\ Valerie Wayda, Ed.D.
}

Department of Coaching and Teaching Studies

Morgantown, West Virginia

2016

Keywords: coach, noticing, perception, coaching education, soccer, youth sports Copyright 2016 Philip James Liversedge 


\begin{abstract}
Coaching Knowledge and Noticing in Youth Sports: Challenging the Assumption of Expertise Philip James Liversedge

Sport is an integral part of the majority of children's lives. Participation in sport can provide children with many physical and psychological benefits. Tasked with coaching children are coaches who are often parents and volunteers. These coaches have a variety of different levels of experience and expertise. A question that must be answered is what are the range of kinds of knowledge that coaches rely upon? This study delves further and attempts to understand how coaches use this knowledge in the act of noticing. Alongside understanding the complexity of coaching this study attempts to demonstrate the individuality and diversity in coaching and how subjective perceptions of a coaching session can be.

The participants in this qualitative study consisted of four novice, four intermediate, and four expert soccer coaches. A multi-layered interview served as the central data collection tool. Coaches watched a 10-minute video and then participated in an unstructured interview followed by a semi-structured interview. The semi-structured interview was guided by notes taken by the interviewer during the unstructured interview.

An inductive content analysis was employed to allow identification of patterns or themes that emerge from the collected data. A three-phase analysis was used: (a) data reduction, (b) data display, and (c) conclusion drawing and verification (Miles \& Huberman, 1994). A constant comparative method (Glaser \& Strauss, 1967) was utilized during the data analysis process to evaluate whether the coded sections of transcribed text were consistent and ensured they belong in their themes and subthemes.

The findings of this study provide domains of knowledge that coaches noticing during a coaching session. Coaches within this noticed with varying degrees of complexity and depth. This study provided insight into nine new areas of knowledge that coaches notice during a coaching session. The complexities and subjective nature of coach noticing are demonstrated through the findings of this study.

Keywords: coach, noticing, perception, coaching education, soccer, youth sports
\end{abstract}




\section{Acknowledgments}

I will be forever thankful to all of the individuals who have supported me throughout this lengthy and enlightening journey. I would not have earned this degree without the support of my family, friends, and professors. Some individuals who have truly provided guidance along my journey need special mention. To my mother, Carolyn Liversedge, for being a lifelong inspiration in dedication and hard work. To my family as a whole, thank you for the love and support you have shared with me whether in your presence or away from you. To my best mate, Philip Gordon, who always gave me a good laugh and was often ready to debate the world of youth soccer with me. To my "partners in crime” at West Virginia University, Dr. Luciana Braga and Dr. Lindsay Hammond, who went through the same experiences and will be my friends for life. To the hardest working lady in the College of Physical Activity and Sports Sciences, Dr. Valerie Wayda, who provided me with nothing but support and encouragement throughout this process. Dr. Malayna Bernstein, for your support and guidance during my dissertation work. Dr. Robert Wiegand, for your pragmatic approach and ability to always discuss the bigger picture. Dr. Sean Bulger, for showing me a realistic world view and giving me a reality check when needed. Dr. Damien Clement, for coming on board this journey into the coaching education world. To everyone who has helped me along this journey, thank you! 


\section{TABLE OF CONTENTS}

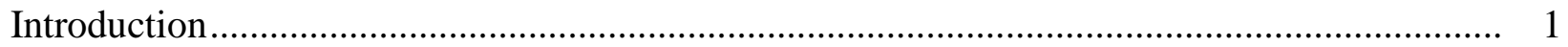

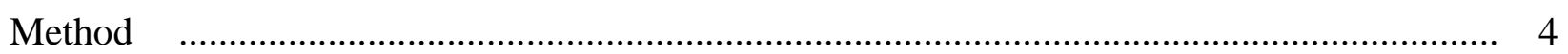

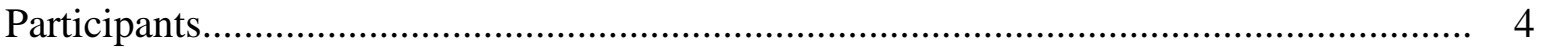

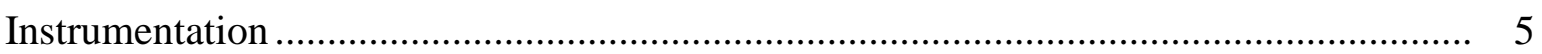

Procedures.................................................................................................. 7

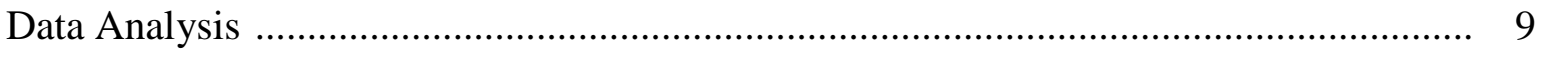

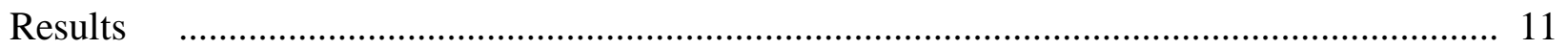

The Range of Knowledge Coaches Rely Upon ........................................................ 11

How Do Coaches Use This Knowledge in the Act of Noticing?.................................. 18

Individuality and Diversity in Knowledge Application.............................................. 24

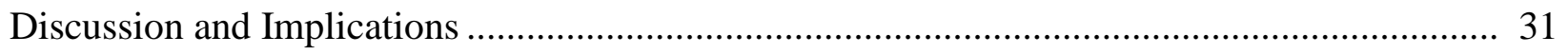

References.................................................................. 36

APPENDIX A: Recruitment Script Interviews................................................................ 39

APPENDIX B: Script for Participant Interview .......................................................... 40

APPENDIX C: Extended Literature Review ..........................................41 


\section{Introduction}

Sport is an integral part of the majority of children's lives. In 2008, Sabo and Veliz estimated that $72 \%$ of American youth participated in some form of exercise and organized team sports. Furthermore, the children who participate in sport were strongly affected in several ways including increased self-esteem, emotional control, problem-solving, goal achievement, social skills, and academic performance (Holt, Kingsley, Tink, \& Scherer, 2011). Research has indicated that coaches have a great influence on the outcomes and experiences of the children who participate in sports (Horn, 2008). The majority of coaches in youth sport programs are volunteers, predominantly parents (Kim, Zhang, \& Connaughton, 2010). Volunteer coaches are generally novices and work alongside coaches with varying level of experience, knowledge, and expertise. Understanding what a sample of coaches' see during coaching episodes would provide some assistance in guiding and educating coaches at all stages. Educating and guiding coaches may aid their progression towards becoming more effective coaches and positively impacting their athletes.

Teaching in physical education and coaching in sport have a large number of similarities (Drewe, 2000). Both teaching and coaching can provide a lasting impact on children. Depending upon the environment and level of coaching it is possible that coaches have a greater influence and impact upon the individuals they are in a position of authority over than a teacher. Recalling his previous experiences as both a coach and teacher Clack (2012) discussed the corrective measures used to motivate athletes and greater demands that coaches can place on individuals both physically and in terms of time constraints. Drewe (2000) examined the relationship between teaching and coaching and found that although both the job of a coach and a physical education teacher encompass the teaching of skills, strategies, and techniques, there is somewhat of a "coach, not teacher" attitude which can hamper cooperation between disciplines. 
As the field of coaching has progressed so has the role of coaches. The modern coach is required to move athletic coaching towards a more educational endeavor (Jones, 2006). The ever-evolving role of a coach should be considered when researching coaching education along with the demands placed on coaches as their job descriptions adjust to meet the needs of millennials and their parents. Understanding what coaches' notice during a coaching episode can provide a lens into what is perceived as important to coaches and demonstrate the complexities of coaching.

The perceptual capacities of four expert and four novice tennis instructors were studied by Woorons (2001). Knowledge is often invisible and can only be showcased when elicited. To elicit this knowledge Woorons (2001) employed a stimulated recall process and found that there were differences between experts and novices in regards to instruction and motor skill analysis yet no difference in the quantity of cues detected. Further findings from the study were that novice coaches within the study had observations that were quite superficial ranging from clothing to location of cars in the parking lot. Experts tended to focus on factors that altered performance assessment and the necessary steps to improve this. Experts were also found to be more methodical and critical than novice instructors. The vast array of aspects of the coaching session that were noticed by coaches demonstrates the extensive and subjective nature of coaching.

Individuals in all fields construct meaning for themselves, and there is no one size fits all approach to learning or constructing meaning. Noticing research can attempt to elicit meaning and knowledge from participants while understanding that it can be a deliberate, conscious process or not (Sherin, Jacobs, \& Philipp, 2011). What teachers see influence their response and this response alters the learning environment providing a unique set of episodes that the teacher 
must then adjust to (Sherin et al., 2011). The work of Kim et al. (2010) demonstrated the majority of coaches working in youth sports are novice volunteer parent coaches, and these novice coaches are tasked with the complexities of an ever evolving learning environment. What this majority of coaches notice guides their reaction to the episode and the learning they provide to their athletes.

Understanding what a sample of coaches’ notice, with a varying level of experience and knowledge, may provide opportunities to advance coaching education. Cushion, Armour, and Jones (2003) indicated that a limited body of research has been compiled that focuses on coaching practices and the influence of experience on this practice. Vickers and Wax (2012) echoed the sentiments of Cushion et al. (2003) when they promoted the importance of future studies in coaching education that investigate coaches with identifiable and varying levels of experience. This study aimed to understand what a sample of coaches’ saw and understand the range of coaching knowledge that they saw. This analysis of a sample of coaches provides an empirical lens into understanding the range of knowledge that coaches along the spectrum of expertise possess, as opposed to previous studies that focus on isolated levels of expertise in coaches.

The purpose of this study was to discover the range and types of knowledge that a diverse set of coaches have and can articulate. Alongside understanding the range and types of knowledge that coaches possess this study attempted to understand how coaches use this knowledge in the act of noticing. Finally, this study aimed to further understand the complicated nature of the ever evolving and very subjective noticing of a coaching episode. 


\section{Method}

This study evaluated novice, intermediate, and expert soccer coaches’ perceptual capacities. Calls within the coaching education literature have requested studies that compare perceptual capacities of coaches (Woorons, 2001). Further calls have requested studies that focus on coaches at identifiable and varying levels of expertise (Cushion et al., 2003; Vickers \& Wax, 2012). This study investigated how a group of coaches, with a range of expertise, perceived a coaching episode and how they can articulate the knowledge that they utilized to discuss what they noticed. This section details the methods that were designed to answer three research questions. First, what are the range of knowledge coaches rely upon? Second, how do coaches use this knowledge in the act of noticing? And third, what is the individuality and diversity in knowledge application? Specifically, this section includes the participants, instrumentation, procedures, and data analysis.

\section{Participants}

As this study was designed to uncover what the range of knowledge coaches have, how they use this knowledge, and how coaches may perceive specific situations as different while utilizing other kinds of knowledge, a total of 12 participants with different levels of expertise were selected. Five female (41.7\%) and seven male (58.3\%) coaches were selected based on meeting criteria that placed them in one of three coach categories: Novice, Intermediate or Expert. Novice coaches were the youngest group of coaches on average (Novice Age $M=26$, $S D=5.18$; Intermediate Age $M=31, S D=8.99$; Expert Age $M=54, S D=17.01$ ). The highest level of educational attainment across the coaches was a high school diploma or equivalent $(n=3)$, bachelor's degree $(n=3)$, and master's degree $(n=6)$. Of those coaches with some post-secondary degree, five coaches (41.7\%) had degrees with an educational focus. Three coaches (25\%) within 
the study worked for a club in-house soccer program that works with recreational level players and four coaches (33.3\%) work for a competitive soccer club coaching travel soccer. Five coaches (41.7\%) were not currently involved with club soccer.

\section{Instrumentation}

Instrumentation consisted of video, unstructured interviews, and semi-structured interviews. The viewing of a video coaching episode was utilized, and Sherin et al. (2011) suggest that viewing and discussing short segments of videos promotes rich discussions relating to teaching and learning. Research by Sherin and Han (2004) indicated that viewing videos of lessons has the potential to uncover and make explicit what teachers at different stages of expertise observe. Through the use of a carefully selected domain specific video, a rich level of data was elicited from participants. The first part of the interview was focused on a purposefully selected 10-minute video clip of a coach performing a soccer session.

An unstructured interview was administered to gain broad themes that coaches noticed during the viewed coaching episode. A stimulated recall is an introspective approach to research and was utilized. De Grave, Boshuizen, and Schmidt (1996) found that an immediate recall procedure prevented participants from exiting the cognitive processes involved in the problem they analyzed and that the verbal interactions had similar characteristics of the think-aloud protocol. Due to attempting to elicit responses from participants relating to their perceptual capacities relating to their knowledge base a stimulated recall method was applicable. Lyle (2003) suggested that stimulated recall is considered a useful mechanism for exploration of cognitive processes.

The semi-structured interview was guided by the notes taken by the researcher relating to the broad themes noticed during the initial interview and aimed to elicit deeper responses 
regarding specific areas of the interview that the coach observed in the video. The researcher categorized their notes into themes, and each theme was discussed as a specific area of the semistructured interview.

The first portion of the interview helped identify what the coaches' see as significant, which provided a window into the particular kind of knowledge that they brought to bear in the act of coaching. The second portion of the interview allowed the investigator to more deeply examine coach’s knowledge within each element. Thus, the multi-layered interview helped establish both the diverse range of elements of coaching knowledge, as well as the depth and complexity of that knowledge, across a range of coaching expertise.

The design of the interview was strategic to elicit a rich level of data. This qualitative interview process aimed to understand the world from the point of view of the subject and to show meaning relating to their experience (Kvale \& Brinkmann, 2009). The unstructured interview covered broad topics that were specified in advance and allowed the interviewer to decide upon the wording and sequence of questions during the interview (Cote, Salmela, Trudel, Baria, \& Russell, 1995).

The semi-structured detailed interview is a technique that is frequently used in qualitative analyses (Patton, 2002). Guidelines were developed to act as an outline of the core areas covered during the interview, with any new question that developed during the interview analyzed in detail (Potrac, Jones, \& Armour, 2002). This interview technique resembles a conversation with the majority of the talking undertaken by the participant (Jiménez, Calvo, \& Ibáñez., 2009). The semi-structured interview was guided by notes taken by the interviewer during the unstructured interview. 


\section{Procedures}

The following section describes the procedures that were used to attempt to answer the research questions. The procedures followed the steps that are described in the instrumentation section including: selection of video, unstructured interview, and semi-structured interview.

The primary investigator (PI) selected four possible video clips; each displayed notable elements of a coaching session, such as a skill development, coach-player interaction, or tactical discussions. Four possible options for videos were observed by a panel of five local soccer coaches, with a range of experience and licensure, and selection was based on a majority decision by the panel. The panel ranked the videos one to four based on the video they believed would be easiest to talk about if they were interviewed. The video with the lowest total was selected for this study as it should have promoted rich discussion from the coach participants regarding common skill development, common coaching mistakes, or highlight moments of significant player development or difficulty. Providing four video clips of soccer sessions to the panel involving four different coaches, settings, age groups, and skills taught provided a range of scenarios and instructional strategies to discuss. Research in teacher education has outlined criteria for selecting videos that elicits rich discussion from teacher (Sherin, Linsenmeier, \& van Es, 2009); one methodological contribution of this study is that it can suggest a similar set of criteria for selecting evocative videos of coaching sessions. The rationale for the panel and video selection was to ensure an ease of discussion when data was collected guaranteeing rich data via a two-stage interview process.

Once the video was selected the study was piloted to ensure it elicited explicit articulations of cognitive knowledge. Upon completion of the pilot, potential coaches were contacted as participants. The novice coaches were contacted via email based on an email list 
from the Director of Coaching at two local soccer clubs. The intermediate coaches were contacted via email from a list serve of West Virginia high school soccer coaches and met the minimum criteria to participate. The expert coaches were contacted via a list of possible participants provided by the Director of Coaching Education for the National Soccer Coaches Association of America (NSCAA). Upon interest being acknowledged by ten possible participants a criteria check was administered to ensure the participants met the specified criteria previously mentioned while providing diversity within the group.

Data collection came via individual interviews completed at a time that was convenient for the participants. All interviews began with instructions adapted from the study by Graham, French, and Woods (1993) and Woorons (2001). Participants were informed: "For the next 10 minutes, you will be watching a video of soccer instruction, the purpose is to have you describe what you observe happening during the lesson. You should find it helpful to take notes while you observe the video. After the video, you will be interviewed".

After observation of the video, the unstructured interview became the central component of the first interview phase. A participant-centered approach was employed, and the unstructured interviews were not guided by the interviewer. During the unstructured interview, the participants were asked to describe what they observed during the soccer coaching video they watched and made notes about. Participants were permitted and encouraged to use the notes that they compiled during the video observation. During this interview when the participants paused during their response the participants were prompted to describe anything which they observed during the video. This continued until the participant indicated that they have exhausted everything that they observed and desire to discuss. During this interview process, the researcher compiled notes on the topics and themes which were mentioned during the interview. The notes 
on topics and themes were used to stimulate areas of discussion within the semi-structured portion of the data collection process.

The semi-structured interview was completed immediately after the unstructured interview was completed and was audio recorded and stored digitally. The semi-structured interview was guided by the participant's response to the unstructured interview and subsequent interviewer notes. The semi-structured interview attempted to link what the participant perceived in the video recorded coaching session and how this related back to their experience and knowledge base.

\section{Data Analysis}

The interview recordings were saved digitally and transcribed verbatim by a transcriber. Each interview was transcribed independently and stored as an individual file in a password protected format that ensures confidentiality. The interviews were coded and then data was analyzed from the three groups that created the larger sample. Data analysis of this study employed an inductive content analysis that allowed identification of patterns or themes that emerged from the collected data.

A three-phase analysis was employed consisting of: (a) data reduction, (b) data display, and (c) conclusion drawing and verification (Miles \& Huberman, 1994). A constant comparative method (Glaser \& Strauss, 1967) was utilized during the data analysis process to evaluate whether the coded sections of transcribed text were consistent and ensured they belonged in their themes and subthemes.

During the data reduction phase, the researcher attributed codes to segments of data according to their meaning and ensured a constantly updated codebook was created. To code the data, a series of codes were created. The literature relating to coaches domains of knowledge 
provided a series of codes for an initial codebook framework. Specifically Santos, Mesquita, Graca, and Rosado (2010) provided a core of domains of coaching knowledge, with additional code refinement based on the importance of experience and support from experienced coaches (Cushion et al., 2003; Gilbert \& Trudel, 2001). All subsequent codes were provided by the data itself. Specifically, a total of ten codes were derived from the literature and an additional ten codes generated through the data itself. The codebook was later condensed to 15 codes through discussions of the research team and consolidation of three codes into a broader category, resulting in 6 derived from the literature and a further 9 generated from the data analysis.

To enhance the depth of the coding process a three-level coding system was utilized. The three levels of coding were extracted from the teacher noticing literature. Noticing has been conceptualized as attending to or making sense of events within the instructional setting (Sherin et al., 2011). The three-level coding system was modified from the work of van Es and Sherin (2002). The three levels utilized were: level one noticing of superficial detail, level two extrapolating meaning from detail, and level three acting upon detail by providing a solution to what they observed. The three-level coding system provided depth to the study which would have been unachievable without taking the depth of noticing into account. This three level noticing is of particular importance when understanding individuality and diversity in knowledge application.

A group of three experienced independent coders were asked to attribute codes to sections of text within one transcribed interview. The independent coders were graduate students in a Qualitative Data Analysis course at a Research Intensive University. A fine-grained microanalysis of that data was conducted to attempt to extract meaning from that data that may be missed in a more superficial analysis. This micro analysis was modified based on fine-grained 
micro analysis utilized by Sherin and van Es in their 2009 study. A debriefing meeting was held with all coders to ensure consistency within the coding. Any sections of texts which were ambiguous in regards to code were shared with the coding group, and discussions took place to assign an agreed upon code, arguing to consensus. Congruency within the findings was checked by the researchers revisiting the themes and subthemes. All statements were provided a code and subsequent numerical value based on the three-level coding system. The second phase of the analysis was initiated once the coders agreed that the themes validly represented the data.

\section{Results}

The following sections answer the three important research questions and are subsequently followed by a discussions and future implications section that aims to provide a guide for future research and implications from this study.

\section{The Range of Kind of Knowledge Coaches Rely Upon}

The literature relating to coaches knowledge provided several domains of knowledge which coaches value, and many of these were found to be of importance and noticed by the participants of the study. Santos and colleagues (2010) provided a large portion of the domains used within the codebook in their work on coaches’ values about coaching knowledge. Six domains (training organization, development of technical skills, instructional strategies and pedagogy, meet athletes' needs, sport specific knowledge, and evaluation of other coaches) were identified through the literature as important domains of coaching knowledge (Cushion et al., 2003; Gilbert \& Trudel, 2001; Hansen, Larson, \& Dworkin, 2003; Martens, 2004; Santos et al., 2010) and they manifested themselves within the present study. The results of this study provided a further lens into what coaches perceive during a coaching episode, and nine additional domains were generated through the analysis including: Coach to player interaction, 
player to player interaction, feedback, equipment, engagement, team building, setting an example, appearance of coach, and professionalism.

Coach to Player Interaction. The coaches interviewed consistently promoted the belief that coach to player interaction is something of importance with all but one coach mentioning coach to player interaction as something that they noticed. Most coaches noticed at level one noticing. An example of this from participant N-2 (Nora) at the level one noticing when discussing the interactions between coach and player is as follows:

"Like I said I think he did it to ease the players into the practice session he gained their attention I think and possibly he gained some trust by including them in the setup of the practice." As Nora discussed how the coach gained the attention and the trust of the players, she also discussed noticing coach to player interaction within the observed scenario.

Feedback. In this study 10 of the 12 coaches noticed feedback from the coach to the players. Most of the noticing relating to feedback was at the level one and level two depths of noticing. In the interviews noticing of positive or negative behavior of the player, their performance of technical skills, or participation in the coaching session occurred. The results indicate that coaches notice whether feedback is provided to players during a coaching session. An example of noticing feedback of performance, and in particular celebrations of goals, comes from participant E-2 (Ernie) at level three noticing:

I noticed one kid liked to do the airplane. You know if you use that reinforcement and say, 'Phil, you know that was a great goal and great celebration,' then maybe the other kids would think I have to get one so I can do one.

When Ernie discusses noticing the child enjoying their celebration and the ability to positively reinforce behavior via the use of feedback this demonstrates noticing during the 
coaching session. Analyzing the noticing at a deeper level this statement discusses the benefits of providing feedback and utilizing this pedagogical concept to encourage the desired behavior, in this case scoring goals so that celebrations can occur.

Equipment. The equipment used within the coaching session was noticed by 11 of the 12 coaches within the study. Noticing of equipment ranged from coaches mentioning the number of soccer balls, the size of soccer balls, the cones used within the session and the type and quality of the goals being used. Noticing of equipment by the participants was mostly at the level one depth of noticing, yet two of the expert coaches provided examples of how they would adjust the equipment to improve the coaching session. An example of noticing at level one noticing relating to equipment from participant E-1 (Eric) when discussing a dribbling activity and soccer balls:

"I liked the ball each and he was doing dribbling so, I could see there were different size balls, that is fine, he probably hadn't got enough size threes or something or size fours, but everyone had a ball."

When Eric discusses the concept of each child having a ball he predominately is discussing the use of equipment and ensuring each child has a ball. Some other domains are discussed within this short statement, and they are meeting athlete's needs by utilizing age appropriate sized soccer balls and that it is developing technical skills through age appropriate practice concepts.

Engagement. Engagement of players was found to be something the coaches within the study noticed. Engagement of the players was discussed by all coaches in the study in relation to players' attention, amount of perceived work, attentiveness, and concentration of the players. Although all coaches noticed and mentioned engagement of the players within the coaching session, very few participants provided noticing that was deeper than level two noticing. Only 
one participant in the study provided noticing about engagement at the level three depth. An example demonstrating noticing at level three by E-3 (Ellis) discusses what was noticed and provides a method to improve the situation of players not being involved and losing interest witnessed in the video:

If I am a parent paying for my kid to be instructed to play soccer and I, see him standing there or sitting on the sidelines not playing that is going to upset me. He is not being engaged so he is may be not motivated, not being instructed properly. I want him to learn I want him to you know be active. Kids need to run around and have fun and blow off steam that is why I say every 2-3 minutes I would be changing activities with kids like this I would have a circle and just go from one game to the next, and you could do the same thing every practice with kids that age.

All coaches within the study mentioned the concept of engagement and Ellis illustrates this point throughout this statement. In the first line his discussion of the player standing on the sideline of sitting out demonstrates a lack of engagement. Ellis explicitly mentions the concept of engagement in the second sentence and progresses in the next sentences to offer methods in which he believes engagement could be increased.

Team Building. Team building is something that was not found to be of major importance in a study into what coaches’ value about coaching knowledge and what type of knowledge they value (Santos et al., 2010). The findings of this study indicate that team building is of importance to almost half of the coaches who participated within the study but not at more than level two noticing. Team building was more of a focus for the intermediate coaches in the study. The experts within the study did not notice team building, or if it was noticed it was not 
mentioned as something they noticed. The importance and benefits of team building were discussed at level three of noticing by participant I-1 (Ian):

There is one thing I do know if you can get the players to bond into it and they come a part of it they are more engaged in the practice, and if they are more like co-leaders in ways or co-participators then they feel like it is necessary to keep other people in line, and they are your team with you instead of just this hierarchy of I am your boss. When they are in it, you get more out of them at times.

Team building was discussed by Ian and the idea of creating a bond between players and how this can increase engagement through the use of peer leadership as opposed to the idea of an autocracy. Ian progresses to discuss how it is possible to elicit more engagement and effort from the players through creating a sense of team building.

Setting an Example. The coach as a role model and setting an example for the players within the coaching session was noticed by five participants within the study, but not by any intermediate coaches. Noticing by the coaches featured behavioral examples, body posture, willingness to demonstrate skills, and passing respect for the game forward. All noticing of setting an example occurred at the level one or level two noticing. An example of noticing relating to setting an example by participant E-2 (Ernie) when discussing respect for the game is: "A certain respect for the game needs to be passed on, so the young kids need to understand the coach is kitted up right, and I need to be kitted up right."

The concept of setting an example is discussed by Ernie when he mentions passing on respect for the game and this being transferred between coaches to players. He includes a discussion of the appearance of coach along with how being "kitted up" sets a good example for players who learn to replicate and respect the game. 
Appearance of Coach. The appearance of the coach was an area that was noticed by half of the participants within the study. The majority of coaches who noticed the appearance of the coach provided solutions and examples of how a coach should look, which was at the level three depth of noticing. No intermediate coaches noticed or mentioned the appearance of the coach. When discussing the appearance of a coach and how the appearance of coach creates a perception of their ability participant E-4 (Esteban) demonstrated a level three noticing response when stating:

Even at six years old as the coach said 'show me what a football player looks like' they know that football coaches don't wear jeans. I think from a perspective point of view a coaches and the players you have got to look like you know what you are doing. If I walked up and a coach was coaching my kid, I would be like, I am not sure he knows what he is doing regardless of his knowledge you have to look like a coach to be able to do it as well.

When Esteban begins to discuss what a footballer looks like is discussing the appearance of the coach and how children have an understanding of what a footballer looks like and what a coach should look like. Esteban continues to discuss the appearance of coaches and how people may question the legitimacy of coaches through appearance and the perception that they do not have the required knowledge base.

Professionalism. The idea of professionalism was noticed by five out of the twelve coaches who participated in the study. Noticing of professionalism included behavior and being organized to run the coaching session. Most noticing by the coaches was at the superficial level. No intermediate coaches demonstrated noticing of the professionalism of the coach within the 
video. Participant N-2 (Nora) provided a level one noticing when discussing professionalism and what was interesting about organization of the coaching session:

"Interesting good helping them get involved early and wanting them to be a part of training and practice and set-up, but it also looked unprofessional that he wasn't ready."

While discussing professionalism Nora begins to discuss the pros and cons of utilizing the players to be engaged in the preparations for the coaching session. Nora mentions that although it is good having the players help organize in one regard, it can look unprofessional that the coach is not set up and ready for the start of the session.

Player to Player Interaction. The concept of player to player interaction was noticed by only a quarter of the coaches participating in the study and always at the superficial level of noticing. A coach in each level of expertise provided a response that noticed player to player interaction. An example of player to player interaction at level one noticing when discussing players helping move a goal is below from participant N-1 (Nancy):

I think it is important for the kids to see like hey the coach was carrying the goal, but we have it in our hands, and we are carrying the goal, it is kind of like soccer honestly the coach kind of gives you some instruction, but it is ultimately can we do the job, can we get it done.

During the interview, Nancy begins to discuss the promotion of player to player interaction and the concept of building unity and team building. Nancy begins by discussing how the coach helps facilitate this player to player interaction and then removes himself from the situation which allows the players to attempt to understand the concept that the players are creating a team and working together to complete tasks, which is the same as a soccer game. 
Table 1 provides a visual schematic of the findings of this study. Additionally, within this schematic domains of knowledge found through the data analysis are illustrated within their theme, along with the additional literature derived domains that were confirmed by this study.

\section{Table 1}

Themes and Domains Used for Coding

\begin{tabular}{ll}
\hline Theme & Domain \\
\hline Social Interaction & Coach to player interaction* \\
& Player to player interaction* \\
Knowledge of Methodology & Training organization \\
& Development of technical skills \\
& Instructional strategies and pedagogy \\
& Sport specific knowledge \\
& Feedback* \\
& Equipment* \\
& Meet athlete needs including fun \\
& Engagement* \\
Athlete Needs & Team building* \\
& Evaluation of other coaches \\
& performance \\
Visual Communication & Setting example* \\
& Appearance of coach* \\
& Professionalism* \\
\hline
\end{tabular}

*Denotes results derived domain and subsequent theme

\section{How Do Coaches Use This Knowledge in The Act of Noticing?}

To understand how coaches use their knowledge in the act of noticing the research team selected three interview exerts that were rich in the range of types of knowledge that were displayed and how that knowledge was being used. Through the use of a fine-grained microanalysis, utilizing similar techniques used in Russ and Luna (2013) and Sherin and van Es (2009), it was possible to analyze the statements to understand the range of types of knowledge and how it was used. Many of the analyzed statements from coaches provided evidence of 
several domains of knowledge used. Below are examples of this along with the fine-grained microanalysis that demonstrates the complexities of knowledge a short quotation demonstrates. Through the microanalysis, it was found that coaches not only use different kinds of knowledge during notice but they organize that knowledge differently in their statements. For example, Nancy, a novice coach works from a bottom-up approach. Nancy arranges her discussion around key details that lead her to some generalized statements about coaching. A quote from participant N-1 (Nancy) discussing the moving of goals illustrates the complexities of coach noticing:

So I think that number 1 it is a kind of team-building exercise to a lesser degree they are 6 or 5. At first, the coach picked it up, and it was kind of who can help me as a fun way to kind of accomplish something as a team which I think is kind of important because on the soccer field you got to come together and play as a team. Especially he kind of started to lead the team and then backed off and at the end he wasn't even holding it, so the kids were carrying the goal completely to the other side. I think it is important for the kids to see like hey the coach was carrying the goal, but we have it in our hands, and we are carrying the goal, it is kind of like soccer honestly the coach kind of gives you some instruction, but it is ultimately can we do the job, can we get it done.

A fine-grained micro analysis of the statement by Nancy demonstrates five different domain codes within the statement. The coach begins to discuss the idea of "team building" in the first sentence. In the second sentence, she mentions the coach to player interaction and equipment through mentioning "at first the coach picked it up, and it was kind of who can help me." By employing knowledge of team building the coach can develop into observing and discussing coach to player interaction. If the coach only saw this as an equipment issue, she would not have seen player to coach interaction in the same way. In the third sentence, the coach interaction is 
moved to player to player interaction as the coach allows the players to develop a sense of autonomy when the coach "backed off." In the second, third, and fourth sentence the coach is discussing the athlete social and personal development through discussing the idea of teamwork with the players understanding that "we have it in our hands, and we are carrying the goal" and the importance of their actions and outcomes as it relates to the bigger picture of soccer. In the fourth sentence, the coach begins to discuss the importance of instruction when the coach discusses the training organization and the fact the players were required to move the goals. Nancy begins by employing a team building lens and progresses to discussing how this team building can be a reflection of the game of soccer.

Nancy goes back and forth between episodes she observed along with utilizing soccer knowledge to create a thorough discussion that could be categorized as working from the bottom up. She mentioned aspects she notices and then uses these to justify what she says and how this relates to soccer. She continues this noticing and providing a rationale of how this relates to soccer and the overarching goal of coaching, which is to teach the children the game and allow them to be independent when playing. Through scaffolding these small concepts, she notices along with her previous knowledge this provided a bottom-up approach which builds on previous knowledge and noticing to create an overarching theme in her statements.

As demonstrated by the exert from Nancy's interview some coaches focus with an analytical eye and attempt to analyze and justify their statements to provide a common theme. A further example of the complexities of knowledge that coaches notice during a coaching session can be seen in the interview with E-2 (Ernie). Ernie was discussing the intricacies of how the coach was working on dribbling with the players and as can be seen by Ernie's quote some 
coaches use their knowledge in a less concrete format and do not provide any structure or overarching theme when they discuss what they noticed:

Oh yes, I liked that actually because I don't know the purpose and what happened previously but he talked about the 'drag back' and 'step over' but I don't know what was one previously but something connected there for those young kids, but I think he said Torres goes fast, isn't that what he said? So again I suppose that is more specific than say let's do the Torres. Now go back to the space one now we are going to really work on space, because this is our space, our spaceship and every time I yell freeze there can’t be anyone that can touch you. Well, that is relatively, what is space? I can touch Phil and Phil can touch me that is not good space. You let me in your space house. Okay, let's start dribbling, stop. Can you touch Phil? No, that is good space that would have been a better method. So I thought he got some connection with the Torres thing.

The coach begins by discussing the development of technical skills in the first sentence when he mentions the coach discussing the "drag back" and "step over" which are both basic fundamental technical skills that are taught to young soccer players. Within the first sentence, he discussed connecting to the children's knowledge and meeting athletes needs when discussing "Torres," who is a famous soccer player and how this connects to the players. What the coach associates with "Torres" is speed, and E-2 (Ernie) breaks down what "Torres" represents to soccer with the children, and that is speed. In the fifth, sixth, seventh, and ninth sentences the coach provides a more appropriate method of teaching the topic which utilizes both an evaluation of other coaches' performances when he mentions “that would have been a better method” and instructional strategies and pedagogy when mentioning "I can touch Phil and Phil can touch me that is good space”. The ninth sentence focuses on soccer specific knowledge and 
the principle of finding appropriate space within the playing area. This is illustrated with "that is good space." The tenth sentence refers to meeting athletes needs by making a connection with a real life role model they can copy when discussing the "connection with the Torres thing." The complexities of coach noticing are illustrated by the five codes that were demonstrated in statements by coach E-2 (Ernie).

A deeper analysis of what Ernie was discussing shows that his knowledge manifests itself in more of a sporadic way than Nancy’s thoughts. Ernie also discusses five domains within his statement but doesn't create any form of overarching concept in the way Nancy did. Where Nancy looked to justify her thoughts and tie it into an overarching theme and discuss how this relates to the game of soccer whereas Ernie seems to combine several different domains and bounces between the themes incorporating some soccer knowledge. Ernie demonstrates a great deal of content knowledge but doesn’t provide this knowledge in any concrete idea or structure.

Through a microanalysis of a third participant, it is possible to demonstrate a different method of structuring knowledge. An excerpt from Eric's interview provides a demonstration of a coach who utilizes a top-down approach and evaluates and then justifies their opinion based upon evidence noticed. A lot of domains can be extracted from a few statements through a finegrained microanalysis; this is demonstrated through analysis of a statement by E-1 (Eric) that covers five domains:

Just experience, coaching is not easy, and if you are not careful you can lose control of what's going on, the better organized you are the use of cones, pinnies, a ball each which I liked and he did use pinnies when he came to his little game which was good. I think it starts with you as a person, personality, voice, and manner to keep attention. The first 
thing the kids do is look at you so I don’t think he should be wearing jeans but that is me being a bit old fashioned.

Eric begins by discussing that "coaching is not easy" and the importance of training organization to ensure a coach doesn't "lose control." He continues and discusses the importance of using equipment to facilitate the organization when discussing the "use of cones and pinnies." Eric provides an evaluation of the observed coach's performance at the end of the first sentence when he discusses how "he did use pinnies when he came to his little game which is good." In the second sentence, Eric discusses the importance of the coach to player interaction and how this aides engagement and is important to "keep attention." In the final sentence Eric discusses the appearance of coach and how the players may react to this, he closes with an evaluation of the coach's appearance and that although he critiques this when he states "I don't think he should be wearing jeans," he admits he may, himself, be old-fashioned.

This brief statement from Eric contrasts with both the utilization of knowledge by Nancy and Ernie. Eric provides, what could be described, a top-down approach. Eric discusses the general challenges of coaching and goes on to justify the general statements with the specific details that he noticed. Nancy begins by providing specific details that she noticed then constructs a larger claim about coaching. Eric never provides generalized statements about coaching but provides three domains which never get linked via a complete idea. Through these three micro-analyzed statements, it demonstrates that a large number of domains of knowledge are utilized through the act of noticing and that different coaches structure their knowledge for different purposes. 


\section{Individuality and Diversity in Knowledge Application}

While different coaches share common types of knowledge, they did not all use this knowledge in similar ways during their observations. To examine individuality and diversity in knowledge application, it was important to see how different coaches came to understand the same moment in the video. Seven coaches within the study noticed the coach in the episode involving his players in moving the goals. With over half (58\%) of the coaches within the study noticing this aspect it was deemed as important by coaches and the research team felt it met the criteria of providing a demonstration of different perspectives and showcasing individuality. In this excerpt of the video, the coach arrives at his coaching session. First, he asks and then instructs the players to help him move soccer goals from where they originally met as a group to the designated playing area that would be used for the coaching session.

Coaches used between two and five domains of knowledge to discuss what they observed in this snippet of the coaching session. The seven coaches who discussed the movement of the goals utilized nine domains of knowledge. Four coaches within the study looked at moving the goals through a positive lens; one coach discussed both the positive and negative aspects, and two coaches discussed negative aspects of utilizing players to move the goals. Isaac (I-2) utilized a positive lens:

Like I said I think he did it to ease the players into the practice session he gained their attention I think and possibly he gained some trust by including them in the setup of the practice. I think it helps to build the concept of team, and you enter the pitch as one group, carrying all the equipment.

When discussing moving the goals I-2 (Isaac) uses three different kinds of coaching knowledge: coach to player interaction, training organization, and team building. Isaac 
discussed how he thought to move the goals was used to "ease the players into the practice" which relates to coach to player interaction and further mentions that it "helps build the concept of team” which relates to the concept of team building. In all three aspects of noticing Isaac utilized a positive lens in all cases, he believes the coach. Isaac noticed and discusses training organization when he discusses how the coach "gained some trust by including them in the setup of the practice." Through noticing and mentioning the aspects of the session that he did, Isaac demonstrates that what he noticed was organized and formed into a positive application of this knowledge utilizing three domains of coaching knowledge.

Irene (I-3) continues in a similar vein as Isaac when she discusses moving the goals and the benefits of utilizing players to help move the goals and notices four domains of knowledge with some different domains observed than in Isaac's interview. The following example from Irene demonstrates that she applied her knowledge in a positive light when asked about why she noticed the players moving the goals and that she felt this had a positive influence on the observed session:

I think that as a coach I am always trying to improve team dynamics are probably more important in soccer than they are in any other sport. You can’t score goals by yourself and especially coaching high school girls you are always trying to get them to mesh better and to do exactly what he did see that they are stronger as a unit than they are separate. The age group that I am with there is a lot of selfishness and people wanting to be 'stars' and success is dependent on having them understand that they are better together.

Irene promoted the idea of team building when she mentioned moving the goals "improve team dynamics” and allows the team to become "stronger as a unit” which promotes team building. Coach to player interaction was focused upon when she mentions that "as a coach I 
am always trying to improve team dynamics" and player to player interaction was discussed when she noted that "coaching high school girls you are always trying to get them to mesh better and to do exactly what he did." Irene discussed meeting athlete needs when she discussed "there is a lot of selfishness and people wanting to be 'stars' and success is dependent on having them understand that they are better together."

Nancy provided a further example of how a coach may view an aspect of a coaching session when she discussed the benefits of the coach making the players move the goals. Nancy utilized a positive lens when she discussed how five domains (team building, equipment, meeting athlete needs, coach to player interaction, and player to player interaction) were utilized when the goals were moved:

So I think that number 1 it is a kind of team-building exercise to a lesser degree they are 6 or 5 . At first, the coach picked it up, and it was kind of who can help me like a fun way to kind of accomplish something as a team which I think is kind of important because on the soccer field you got to come together and play as a team. Especially he kind of started to lead the team and then backed off and at the end he wasn't even holding it, so the kids were carrying the goal completely to the other side. I think it is important for the kids to see like hey the coach was carrying the goal, but we have it in our hands, and we are carrying the goal, it is kind of like soccer honestly the coach kind of gives you some instruction, but it is ultimately can we do the job, can we get it done.

Nancy began by discussing team building that she perceived she witnessed as a "teambuilding exercise." She progressed to discuss equipment and how the “coach picked it up” and integrated the children to meet athlete needs concept into helping the coach while it was a "fun way" to involve the players. Nancy discussed coach to player interaction when she mentions 
how the coach eventually "wasn't even holding it, so the kids were carrying the goal completely to the other side." She closed her statement through a discussion of how this related to the game of soccer and player to player interaction where the "coach kind of gives you some instruction but it is ultimate can we do the job." While Nancy took a positive stand as to the benefits of moving the goals and demonstrating her individuality and diversity in knowledge application Ned (N-3) provided a different interpretation of what he saw during the moving of the goals and how he applied this knowledge from four domains:

I just find that it is easier to have the children interact with you with every scope of what's going on on the field especially with equipment as well as playing because they need to know how preparation takes place and also just helping in general, kids like to know that they can be helpful.

Ned began by discussing coach to player interaction when he mentioned that "it is easier to have the children interact with you with every scope of what's going on." He continued to discuss the benefits to having the players help with equipment and training organization as it allowed the children to "know how preparation takes place." Ned promoted the idea of meeting athlete needs when he discussed that "kids like to know that they can be helpful." Ned discussed coach to player interaction through his discussion of the having the children being involved in the setup and how "preparation takes place." This provided a method for children to learn what is required for the session as opposed to the team building concept that was promoted by other study participants.

A further example of differing interpretations was Nora (N-2). Nora discussed the positives and negatives of the players being integrated in moving the goals and utilized four 
domains of knowledge (training organization, coach to player interaction, evaluation of other coaches, and professionalism):

Normally it is all set up prior when I have coached, and you wait for the kids to get there and you are ready to go, but it seemed like he wanted them to help which I thought was interesting. Interestingly good kind of helping them get involved early and wanting them to be a part of training and practice and set-up, but it also looked unprofessional that he wasn’t ready.

Nora began by discussing how the training organization she used resulted in the coach setting up the field and that as a coach "you are ready to go." She commented that it seemed like the coach "wanted them to help," demonstrating coach to player interaction. Nancy continued that this was "interestingly good" to her and that this was "helping get them involved early" through being a part of the training organization. In closing, she noted that this also "looked unprofessional that he wasn’t ready” which demonstrates an evaluation of the coach and professionalism. Nora demonstrated a balance of both positive and negative comments relating to the players moving the goals at the start of the session. Whereas other coaches provided a positive or negative discussion of what they saw.

Two coaches utilized their knowledge and applied it towards a negative critique of what they observed when the coach in the video asked the players help him move the goals. Ellis (E-3) comments that the training organization and equipment set up took a long time which results in less time for the players to participate:

It probably took them a good few minutes to get over to the field you know, the explanations, picking up the goals and getting them over there. So you know if they are 
getting organized they are not playing I always like to get into the activity as soon as possible.

Ellis discussed the two domains of training organization and equipment when he mentioned: "picking up the goals and getting them over there." He further discussed how when "getting organized they are not playing" and provided a way he likes to organize things with his ability to "get into the activity as soon as possible." This critique demonstrates his individuality when discussing what he perceived as time that could be spent with the players playing as opposed to helping organize the training session. A further diverse application of knowledge is discussed by Esteban (N-4) when he discussed four domains (training organization, engagement, equipment, and meeting athlete needs) and the moving of the goals:

I think it is important that you have the stuff set up beforehand that you can go right into the session. I honestly think that in terms of safety carrying a goal with twenty little kids running around is not the best thing to be going on. It also helps you get into your exercises quicker, it allows you to get the kids playing without having to carry gear. Again just from working with young kids the less organized you are, the slower the sessions are the players get bored, it is just important to get them playing as quickly as possible that is what they are there for, they are not there to help you carry goals, cones, balls, and pinnies.

Esteban began by discussing his beliefs regarding training organization and that the session should be "set up beforehand and that you go right into the session" which is similar to the thoughts of Ellis. When discussing the "players get bored," Esteban was discussing engagement of the players. Meeting the athlete needs was discussed by Esteban when he noted: "it is important to get them playing as quickly as possible that is what they are there for." 
Esteban noticed and organized his knowledge differently than Ellis and other participants when he discussed how safety concerns him and that "carrying a goal with twenty little kids running around is not the best thing to be going on." Esteban finished with a discussion of equipment with the players being asked to "help you carry goals, cones, balls, and pinnies."

Through comparisons of the seven participants and the nine domains of knowledge that they discussed diversity and individuality of knowledge application were demonstrated. Although some participants noticed similar aspects and applied their knowledge in a positive or negative manner, diversity was detected between participants. Coaches noticed between two domains of knowledge and five domains of knowledge during the snapshot of the session. A total of nine different domains of knowledge were noticed by the seven coaches who demonstrated that coaches saw and interpreted different things when observing the same small segment of the session.

The four coaches who looked at the snapshot through a positive lens tended to focus on coach to player interaction, with all participants noticing this. Team building was of prominence with three of the four coaches noticing this and in particular the positive facilitation of this through the moving of the goals. Through a combination of coach to player interaction and its positive influence on team building it demonstrates, to these coaches, they go hand in hand. The two coaches who viewed the session through a negative lens focused on the both training organization and equipment used during the snapshot of the session. Nora, who viewed both positive and negative aspects of the session was consistent with the main domains of knowledge for the four coaches who viewed the session through a positive lens (coach to player interaction) and the two coaches who viewed the moving of the goals by players through a negative lens (training organization and equipment). 


\section{Discussion and Implications}

The findings of this study support previous findings within the coaching education literature (Cushion et al., 2003; Gilbert \& Trudel, 2001; Santos et al., 2010) and promote further domains of knowledge that coaches noticing during a coaching session. The work of Santos and colleagues (2010) was supported by the results of this study which confirmed their findings of the six domains of knowledge and their importance to coaching education and research within the field.

This study provided insight into the following new areas of knowledge that coaches notice during a coaching session: coach to player interaction, player to player interaction, feedback, equipment, engagement, team building, setting an example, appearance of the coach, and professionalism. These aforementioned nine domains should be stranded throughout coaching education to allow coaches who participate in these courses to understand the complexities of what they will be tasked with understanding. Further research within the field should focus on how the aforementioned domains noticed manifest themselves in coaches with a defined range of expertise. The criteria utilized for coach selection including defined levels of experience and coaching education provide a structure for coach selection for future studies. A limitation of this study is that the sample of coaches was relatively small, although diverse in regards to experience and coaching education. Responsive to students- suggests that coaching educators need to inquire and be responsive to the kinds of knowledge that students arrive with. Extensive bodies of knowledge that can contribute to development of these student coaches. Student-centered and responsive to what students come in with and how we can leverage and build upon that knowledge. 
This study promotes the use of fine-grained microanalysis in qualitative studies relating to coaching education as this demonstrates the complexity of the inner workings of coaching. The method that was employed within this study enabled the researchers to analyze deeply statements within the study and demonstrate how coaches use the domains of knowledge in the act of noticing, borrowing from the ideas of teacher noticing (Sherin \& van Es, 2009). Coaches within this study were found to use and organize knowledge differently when in the act of noticing. A large amount of domains utilized by coaches demonstrates the complexities of coach noticing and should be researched more when controlling for experience, coaching education, and gender. The organization of these domains of knowledge is something of significant importance. Ernie (E-2) is an extremely important case that demonstrates that knowledge itself is important, but there must be structure towards the knowledge. Nancy $(\mathrm{N}-1)$ provides a very analytical mind that even though she is a novice coach she attempts to suggest a larger argument based upon her knowledge that may have some hierarchical structure of knowledge. Ernie, although an expert coach in this study, does not provide any structure to his thoughts. Eric (E-1) provides an overarching structure of thoughts that are backed up by domains of knowledge that he noticed within the study. One of Tan's (1997) characteristics of expertise is that experts possess hierarchical organization of knowledge, and this should be explored further by future research. The varied organization of knowledge that is demonstrated in this study should be taken into consideration by coach educators. Providing opportunities for coaches to formulate and demonstrate their structure of knowledge as opposed to being provided a one size fits all approach to coaching education may provide opportunities for diversity of thinking within the field. Further research could be conducted to provide research as to which organizational structure is most prevalent within coaches to provide other methods of learning for coaches with 
different knowledge organizational structures. In the same way, effective coaches provide learning opportunities for kinesthetic, visual, auditory, and analytic learners coach educators must provide a variety of strategies to support learning of coaches with different knowledge organization structure.

The complexities of the act of coaching are demonstrated through the numerous domains of knowledge noticed by coaches within the study. With the majority of coaching being completed by individuals who are volunteer coaches with no coaching education and limited experience this demonstrates the challenges that face these individuals on a daily basis. All coaches are tasked with examining and adjusting to an ever evolving environment in order to enhance learning, yet the vast majority are inexperienced coaches with no coaching education that would provide these coaches some form of content knowledge or pedagogical content knowledge. Coaching education should provide awareness to learners as to the different themes and domains of knowledge which they will encounter in order to allow these learners to have a basic understanding of what they may notice.

The subjective nature of the coaching world is something that is fully illustrated within this study. When discussing the movement of goals the individual and diversity of knowledge application was showcased. Participants within this study observed the moving of the goals and connected it to a variety of different domains of knowledge. Coach educators should provide a method for learners to understand why they notice numerous domains of knowledge via a small observation, and that their perspective is valid even though it may be different to that of the traditional or majority consensus. Research within the field should focus on understanding how the domains of knowledge are related and how this impacts coaches’ perspectives. 
Alongside interpreting what they noticed during the coach having the players move the goal some coaches believed what they viewed was a positive, a negative, and one coach thought it was both. Although this was only one snippet of the coaching session which lasted a small proportion of the video it demonstrated by the subjective nature of coaching, how coaches can interpret very different things, and the complexities of the organic coaching environment. Coaching education should ensure an open philosophy as to positives and negatives regarding observed aspects of a coaching session. A one size fits all approach should not be prescribed and a rationale should be offered for a variety of acceptable perspectives. Further research should provide a larger sample size and how a positive, negative, or balanced perspective manifests itself in a group of coaches with a variety of expertise.

A large number of domains of knowledge were demonstrated in the act of noticing and the number of domains of knowledge was not in correlation with expertise, coaching education level, and experience. Coach educators should devise specific content for youth sports that isn't generalized and is age specific and appropriate for all age groups coached. Coach educators should also safeguard within their courses that novice, intermediate, and expert coaches notice different things and utilize a variety of domains of knowledge during their observations of their sample sessions. Future research in the field should embrace the shift in dynamic that challenges the notion of expertise and that would assume expert coaches would notice more domains of knowledge than less qualified and experienced coaches.

One of the aims of this study was to problematize and add nuance to the notion of coaching expertise. The more one is able to articulate and represent the depth and complexity of our discipline the greater respect coaches will have and efficient our design of coaching education can be. Therefore, the research team encourages people in the field to continue to 
challenge and articulate the diverse range of type of knowledge coaches have. This may be accomplished through looking across several subthemes in coaching education and similar fields. For example, what knowledge is distinct between coaches of individual and team sports? What coaching knowledge transcends sports? The more we are able to articulate and represent our specialist content and pedagogical content knowledge the greater we can grow and improve the field, while gaining respect for the complexities of coaching. 


\section{References}

Clack, J. (2012, December). Teaching and coaching. Bioscene: Journal of College Biology Teaching, 37(2), 48-49.

Cote, J., Salmela, J.H., Trudel, P., Baria, A., \& Russell, S. (1995). The coaching model: A grounded assessment of expert gymnastic coaches' knowledge. Journal of Sport and Exercise Psychology, 17(1), 1-17.

Cushion, C.J., Armour, K.M., \& Jones, R.L. (2003). Coach education and continuing professional development: Experience and learning to coach. Quest, 55(3), 215-230.

De Grave, W.S., Boshuizen, H.P.A., \& Schmidt, H.G. (1996). Problem based learning: Cognitive and metacognitive processes during problem analysis. Instructional science, 24(5), 321341.

Drewe, S.B. (2000). An examination of the relationship between coaching and teaching. Quest, 52(1), 79-88.

Glaser, B.G., \& Strauss, A.L. (1967). The Discovery of Grounded Theory: Strategies for Qualitative Research. New York: Aldine.

Graham, K.C., French, K.E., \& Woods, A.M. (1993). Observing and interpreting teachinglearning processes: Novice PETE students, experienced PETE students, and expert teacher educators. Journal of Teaching in Physical Education, 13, 46-46.

Hansen, D. M., Larson, R. W., \& Dworkin, J. B. (2003). What adolescents learn in organized youth activities: a survey of self-reported developmental experiences. Journal of Research on Adolescence, 13(1), 25-55. 
Holt, N. L., Kingsley, B. C., Tink, L. N., \& Scherer, J. (2011). Benefits and challenges associated with sport participation by children and parents from low-income families. Psychology of Sport and Exercise, 12(5), 490-499.

Horn, T. S. (2008). Coaching effectiveness in the sport domain. In T. S. Horn (Ed.), Advances in Sport Psychology (pp. 239-267). Champaign, IL: Human Kinetics.

Jiménez Sáiz, S., Calvo, A. L., \& Ibáñez, S. J. (2009). Development of expertise in Spanish elite basketball coaches. Revista Internacional De Ciencias Del Deporte, 5(17), 19-32.

Jones, R. (2006). The sports coach as educator: Reconceptualising sports coaching. International Journal of Sports Science and Coaching, 1(4), 405-412.

Kim, M., Zhang, J. J. \& Connaughton, D. (2010). Modification of the volunteer functions inventory for application in youth sports. Sport Management Review, 13(1), 25-38.

Kvale, S., \& Brinkmann, S. (2009). Interviews: Learning the craft of qualitative research interviewing. London: Sage.

Lyle, J. (2003). Stimulated recall: A report on its use in naturalistic research. British Educational Research Journal, 29(6), 861-878.

Martens, R. (2004). Successful coaching. Qualitative Data Analysis. Champagne, IL: Human Kinetics.

Miles, M., B., \& Huberman, A., M. (1994). Qualitative data analysis. Thousand Oaks, CA: Sage. Patton, M. (2002). Qualitative Evaluation and Research Methods. Thousand Oaks, CA: Sage. Potrac, P., Jones, R., \& Armour, K. (2002). “It’s all about getting respect”: The coaching behaviours of an expert English soccer coach. Sport, Education and Society, 7(2), 183202. 
Russ, R. S., \& Luna, M. J. (2013). Inferring teacher epistemological framing from local patterns in teacher noticing. Journal of Research in Science Teaching, 50(3), 284-314.

Sabo, D. and Veliz, P. (2008). Go Out and Play: Youth Sports in America. East Meadow, NY: Women’s Sports Foundation.

Santos, S., Mesquita, I., Graça, A., \& Rosado, A. (2010). Coaches’ perceptions of competence and acknowledgement of training needs related to professional competences. Journal of Sports Science \& Medicine, 9(1), 62.

Sherin, M. G., \& Han, S. Y. (2004). Teacher learning in the context of a video club. Teaching and Teacher Education, 20(2), 163-183.

Sherin, M., Jacobs, V., \& Philipp, R. (2011). Mathematics teacher noticing: Seeing through teachers' eyes. London: Routledge.

Sherin, M. G., Linsenmeier, K. A. \& van Es, E. A. (2009). Selecting video clips to promote mathematics teachers' discussion of student thinking. Journal of Teacher Education, 60(3), 213-230.

Sherin, M. G., \& Van Es, E. A. (2009). Effects of video club participation on teachers' professional vision. Journal of Teacher Education, 60(1), 20-37.

van Es, E. A., \& Sherin, M. G. (2002). Learning to notice: Scaffolding new teachers’ interpretations of classroom interactions. Journal of Technology and Teacher Education, 10(4), 571-596.

Vickers, B. \& Wax, B. (2012). Modes of learning utilized by coaches to increase knowledge and understanding. Sport Science Review, 21(5), 97-111. 


\section{APPENDIX A}

Recruitment Script 1: Invitation to Participate Letter

\section{Dear Coach,}

This letter is a request for you to take part in a research project to explore the perceptual capacities of coaches along a trajectory of expertise, and how this relates to their knowledge base. Philip Liversedge, is conducting this study under the supervision of Dr. Robert Wiegand, a full professor in the College of Physical Activity and Sport Sciences, in partial fulfillment of the requirements for a doctorate degree in Coaching and Teaching Studies. The study includes participating in two, back-to-back interviews, each of which should take approximately 30-60 minutes.

The interviews for this study will be audio recorded, and all information will be kept confidential and stored on a password-protected file. If a publication results from this study, neither your name nor any other information that may identify you will be published. Participation in this interview process is completely voluntary and you can withdraw from the study at any point. You can also skip any of the questions you do not want to answer. This study has been reviewed and I have received permission to conduct it from West Virginia University’s Institutional Review Board (\#TBD). For questions regarding this protocol, you can reach WVU's Office of Research Integrity and Compliance at (304) 293-7073.

If you have any questions or concerns, please feel free to contact my advisor, Dr. Robert Wiegand or myself.

Sincerely,

Philip Liversedge, M.L.A

Primary Investigator

West Virginia University

Dept. of Coaching and Teaching Studies

pliverse@mix.wvu.edu

570-786-7117
Dr. Robert Wiegand, Ed.D.

Dissertation Chair

West Virginia University

Dept. of Coaching and Teaching Studies

Robert.wiegand@mail.wvu.edu

304-293-0854 


\section{APPENDIX B \\ Script for Participant Interview \#1}

Hello, my name is Philip Liversedge and I am conducting this research as a requirement for completion of my doctoral studies. Thank you so much for taking the time to speak with me today. The purpose of this discussion is to gain a better understanding of the perceptual capacities of coaches at different stages of a trajectory of expertise, and how this relates to their knowledge base.

During the interview today, you will be asked to share your personal thoughts and what you perceived having watched a video. The second second of the interview will be guided by questions and prompts. This discussion will be audiotaped and I will be taking notes throughout the interview in order to use in the second half of the interview. All information will be kept confidential and stored on a password protected file. If any publication results from this study, neither your name nor any other information that may identify you will be published. Participation in this interview process is completely voluntary and you can withdraw from the study at any point. You can also skip any of the questions you do not want to answer. Additionally, if for any reason, you need a break during the interview, just let me know and we can pause our discussion. This study has been reviewed and I have received permission to conduct it from West Virginia University’s Institutional Review Board (\#TBD). Do you have any questions before we begin?

"For the next 10 minutes, you will be watching a video of soccer instruction, the purpose is to have you describe what you observe happening during the lesson. You should find it helpful to take notes while you observe the video. After the video you will be interviewed”. 
APPENDIX C

\section{Review of Literature}

In Coaching Education an important question has been what the differences are between expert soccer and novice coaches’ pedagogical observation skills? If a coach has expertise then that individual has "the possession of a large body of knowledge and procedural skills” (Chi, Glaser, \& Rees, 1982, p. 8). An intrinsic desire to learn about the development of expertise prompted this study including questions related to how does expertise develop, and how does one's capacity to observe the intricacies of pedagogy differ?

The purpose of this study is to determine how coaches' capacity to observe the intricacies of pedagogy differ. The purpose of this chapter is to provide a thorough review of the previous research in the expertise, teacher expertise, physical education teacher expertise, and concluding with coaching expertise. The literature review uses Tan’s (1997) theoretical framework for the elements of expertise to illustrate physical education teacher and coaching expertise.

\section{Expertise}

Research into expertise has been vast and encompasses many different disciplines. Expertise research has garnered a large knowledge base, some which transfer interdisciplinary. Research into expertise has been prominent for over 30 years. Early research was carried out in chess (deGroot, 1978), physics (Chi et al., 1981), computer programming (Soloway et al., 1988), and athletics (Huber, 1997). The ever increasing body of information regarding expertise has provided some insight into how experts are created, what characteristics they possess, and how they differentiate themselves from non-experts.

In all fields there are individuals who perform consistently at higher levels when compared to others. Individuals who consistently perform better than others have been referred 
to as gifted, superior, talented, or expert (Ericsson \& Smith, 1991). Varying degrees of expertise can be demonstrated in almost all human actions and at the pinnacle of this performance are experts. These experts make a momentous investment to their desired domain in terms of time and performance. A regularly pondered question is: “Are the qualities which consistently high performing individuals (experts) possess a product of nature, nurture, or a combination?”

\section{Creation of Experts}

If a formula for creating an expert could be found there would be a vast increase in experts within all fields. Tan (1997) believes that within expertise, talent and the individual's heritage may be influential factors. There is little evidence to suggest that expertise comes purely via heredity or birthright and expertise appears to evolve from a stable set of traits, increasing with experience and practice (Ericsson \& Charness, 1994). The creation of these experts via a stable set of traits, an increase in experience, and practice does not create a defined pathway. Ericsson’s (1993) much publicized notion of 10,000 hours, and the theoretical framework presented in his article, claim expert performance as the end result of an individual's prolonged effort to improve performance while navigating external influences and motivation. Although Ericsson's framework is much promoted there are variations in the dedicated practice with Chase and Simon (1973) estimating that to become a chess master an individual must spend between 10,000 and 20,000 hours. While heredity, prolonged effort, practice, external influences, and motivation may be factors that influence the development of expertise the characteristics that are developed and showcased by experts are important to consider when researching experts and novices. 


\section{Characteristics of Experts}

Experts are the best within their domain and demonstrate a set of characteristics which are unique and differentiate them and aid in their sustained success (Ericsson, 2006). Early research into expertise has provided somewhat of a characteristic portrait of what these experts possess. The common qualities that experts possess have been frequently promoted in the literature. Characteristics that set experts apart from non-experts can be condensed into seven distinct qualities (Glaser et al., 1988). The seven characteristics include: (a) excellent domainspecific knowledge, (b) structured organization of knowledge, (c) quick problem solving within domain, (d) superior memory, (e) deeper problem solving, (f) analysis and understanding of problems qualitatively, and (g) self-monitoring skills. Although common characteristics can be found and promoted it is not merely a case of identifying these characteristics and then promoting them. It is important to remember that each expert is an individual from a specific field who has been guided and altered via a pathway they have taken throughout their journey toward being an expert. No matter what discipline an expert's focus is in many have received help along this journey via a mentor, coach, or teacher.

\section{Teacher Expertise}

Tan (1997) found that evaluating what is known about experts within a variety of domains has been helpful for identifying qualities that expert teachers and coaches possess. Researchers of teacher educators have proposed that through understanding the characteristics of expert teachers, and teachers who are effective (Hansen, 2008; Shulman, 1987), this provides a framework towards some of the characteristics novice teachers could aim to attain. It has been proposed in the literature that inexperienced individuals should not be, and cannot be, required to 
comprehend what experienced teachers or scholars do and the reasons why they do this

(Addams, 1990; Everhart et al., 2013; Hansen, 2008).

Early literature evaluating teaching expertise was completed by Berliner (1986) and used the comparison between experts and novices. Berliner found that expert teachers make inferences about objects and events, they categorize problems to be solved at a higher cognitive level than novices, and they use higher order systems to analyze problems. It was also found that experts are opportunistic planners, have self-regulation capacities, have fast pattern-recognition capabilities, can anticipate well, are student oriented, and establish routines that aid instruction.

The body of research on teacher expertise was increased further by Berliner (1988) when he found that expert teachers were more easily able to distinguish between what is and is not significant within the classroom environment. Berliner also proposed that the expert teachers that shows a fluid performance, may demonstrate an intuitive response and there is variation in where and what they direct their attention towards.

Researchers have assessed expertise by comparing novices, advanced beginners, and experts. Comparisons between novices, advanced beginners, and experts in the field of teaching have been commonplace. For example, Sabers, Cushing, and Berliner (1991) presented a video of the same lesson, from three different angles, to the three different levels of teachers. The authors found that novices have difficulty monitoring all three screens, made errors when asked about specific events, and made contradictory statements. Advanced beginners were found to experience difficulty in providing explanations, often contradicted themselves, and made sense of what was happening within the lesson. Experts were found to have no difficultly or confusion making sense of their observation. Their response were categorized as effortless and fluid. The comments they provided were more detailed, descriptive, and interpretive relating to their 
classroom experience. Experts were also able to monitor both the students and teacher, the three screens, and find both auditory and visual cues. The improved level of monitoring provided the experts with a better opportunity to interpret, evaluate, and make predictions regarding events in the classroom. Further comparisons by Sabers et al. (1991) comparing novice and advanced beginners to experts found that novice and advanced beginners tended to give a step-by-step account of what they saw happening in the lessons which supports the work of Glaser et al. (1988) that there is a deeper understanding and analysis of problems qualitatively by experts than novices.

Carter, Cushing, Sabers, Stein, and Berliner (1988) provided a series of slides depicting pictures of a class period to novice, advanced beginners, and experts. The research provided further evidence towards the contradictory statements of novices and no pattern in what elicited comments from both advanced beginners and novices. The experts were found to have a pattern in what was commented on and similar comments relating to what they saw. The greater levels of uniformity of the interpretations by the experts' shows that they have learned to interpret visual cues in a consistent way that advanced beginners and novices have not advanced to.

Further research in the field of teacher expertise also found that there are differences between the ways novice, advanced beginner, and experts perceived classroom information (Peterson \& Comeaux, 1987; Sabers et al., 1991). Experts tend to distinguish easily between the atypical occurrences and the typical; they also generally responded to the atypical. Stein and Berliner (1988) compared experts’ thoughts during interactive instruction with those of novices, advanced beginners and experts. Experts were found to most frequently focus on student academic work and cognition when compared to the other levels of experience. Further experts use a framework geared towards the promotion of student learning and productivity can be found 
in the work of Claridge (1988) who found that teaching performance of experts focused more on student classroom activity when compared to novices and advanced beginners.

Berlinger (1988) provided a succinct summary that focuses on teachers who are in the early stages of developing their pedagogy skills. Teachers in the early stage of development: demonstrate variation in what they pay attention to, their interpretations and perceptions are different than those with more experience, do not predict or make assumptions as frequently as more experienced teachers, and do not use the same framework for understanding classroom information as those more experienced.

Research by Chen and Rovengo (2000) demonstrated differences in expert and novice teachers' decision making, analysis of events within the classroom, use of routines, content knowledge, and perception of student characteristics. Expert teachers have been found to possess a higher level of perceptual characteristics than novice teachers. Research has also shown that experts have a more varied and better organized knowledge of facts regarding their specific domain than novices do (Leinhardt \& Greeno, 1986). The increased level of domain specific knowledge allows expert teachers to interpret classroom situations and to diagnose student thinking (Borko, 2004). The greater level of domain and pedagogy specific knowledge of experts compared to novices, allows a greater impact on student learning. Much research has been carried out into both the classroom setting and the gymnasium setting.

\section{Physical Education Teacher Expertise}

Tan (1997) identified seven common characteristics of experts within multiple disciplines. These characteristics appear to be based in part on the work of Glaser et al. (1988) and Berliner (1994). According to Tan (1997), the characteristics common in experts were: (a) extensive domain specific knowledge base, (b) hierarchical organization of knowledge, (c) acute 
perceptual capacities, (d) problem representation and solving, (e) automaticity of behavior, (f) extensive memory in their domain, and (g) self-monitoring. Tan's theoretical framework has been used to guide expertise research in the physical education context. Woorons (2001) used this theoretical framework to analyze expert and novice tennis instructors’ perceptual capacities. The framework was also used by McCullick et al. (2006) in their research analyzing the working memories of expert sport instructors. The use of Tan’s (1997) theoretical framework provides some credence to the importance of the characteristics he provides. This section of the chapter focuses on research supporting each characteristic.

Extensive Domain Specific Knowledge. Tricot and Sweller (2014) defined domainspecific knowledge as "memorized information that can lead to action permitting specified task completion over indefinite periods of time” (p. 266). Domain specific knowledge within physical education (PE) often arises via an individual's experiential database. This experiential database begins at an early age and progresses and expands with experience. Some of these experiences can include: participation in physical education classes, observations of physical educators, experiences as a student teacher, learned content knowledge, pedagogical content knowledge, experience as a teacher, and continuing professional development. The bulk of domain specific knowledge is provided within the content knowledge component and the pedagogical knowledge component, which is taught within physical education teacher education programs.

Teachers must be knowledgeable and it is important they know how to use this knowledge (Wood, 2007). Tan (1997) argued that expertise is very much domain specific. Siedentop and Eldar (1989) also believed that expertise is content and subject matter specific and that expertise is often developed in the specified context via experience. Through increased knowledge and experience PE teachers are able to become highly effective and even develop into 
experts. Knowledge and experience is provided within progression through a PETE program and the professional teaching experience, or practicum. Experience as a student teacher and as a professional teacher is invaluable to the development of expertise. Although experience is a key component of expertise it is not the singular act that allows expertise to develop (Siedentop \& Eldar, 1989).

According to Tan (1997) it is proposed that experts, and those who seek to be experts, undergo extended periods of active learning. Encouraging teachers to be professional and active learners will provide their students with an increase in valuable learning outcomes in PE (Armour \& Yelling, 2004; Wood, 2007). You (2011) argues that as teachers become professional learners this enhances a teacher's desire to improve their teaching of physical education. An increased desire to enhance teaching abilities will enable the opportunity for teachers to work towards positively impacting student learning. Recent studies in physical education by Kim (2012) and Lee (2012) demonstrated some evidence that improvements in physical education teachers’ domain specific knowledge, which includes specialized content knowledge, can result in improvements in student achievement. Improving student learning and achievement is a goal of physical education and if this can happen through an increase in domain specific knowledge then promoting methods to increase this knowledge should occur.

Hierarchical Organization of Knowledge. Experts retain the vast amount of knowledge that is gained via experience as structured patterns within their memory, and this knowledge allows experts to compare current events to performance standards previously experienced (Tan, 1997). Once an expert realizes that the current events they are witnessing are different from the performance standards they have experienced previously they will know a change should be made. Research has demonstrated that physical education experts and novices think in different 
ways when providing instruction within lessons (Griffey \& Housner, 1991; Housner \& Griffey, 1985; Rink, 2003; Siedentop \& Eldar, 1989). Providing instruction within physical education, and other teaching disciplines, is a vital component of teaching. Although instruction is of paramount importance during teaching, being able to provide instruction can be challenging. Effective instruction is often the product of effective pedagogical content knowledge and experience.

Rink, French, Lee, Solmon, and Lynn (1994) used a concept map approach to attempt to understand how the knowledge structures of preservice teachers progress as experience and expertise is attained. The pedagogical knowledge structures regarding effective teaching was compared between preservice teachers, experienced preservice teachers, and teacher educators. The preservice teachers were at two different institutions and at different points within their physical education teacher education programs. Beginning preservice teachers $(n=10)$ had completed an effective teaching course and at the other institution the preservice teachers $(n=16)$ had completed a beginning instructional skill course. The experienced preservice teachers at each institution ( $n=32$ ) were about to enter student teaching placements having completed all other coursework. The concept maps completed by the participants were compared and both the quantitative and qualitative data revealed differences between preservice teachers, experienced preservice teachers, and teacher educators. Findings of the study reveal that experts tend to organize their knowledge and information into meaningful categories or units when compared to preservice teachers.

The ability to organize and access knowledge in an efficient and effective way allows a fast response to the every changing dynamics which may challenge an expert. Tan (1997) argues that experts are able to use relatively small pieces of information that act as a catalyst to access a 
larger body of concepts, skills, ideas, and sub-skills. The ability to use small pieces of information to access a larger body of information allows expert teachers to assess instructional episode and make informed decisions which lead to exceptional performance (Tan, 1997).

Acute Perceptual Capacities. Experts recognize patterns within their performance that enables them to utilize their extensive knowledge base and allows them to see information or details that non-experts miss or dismiss (Tan, 1997). To perceive and understand what is happening in a situation the patterns are often recognized via cues. These cues can come in the form of words, movements, or sounds, and can be seen as the event progresses in front of the teacher.

Research by Nelson (1988) supports the work of other teacher expertise researchers and found that expert physical education teachers can interpret more visual cues from limited information provided, which allows them to make inferences and garner more meaning from the cues. Nelson's research and the aforementioned teacher expertise research (Peterson \& Comeaux, 1987; Sabers et al., 1991) provides some evidence to support the belief that novices have a bottom-up approach to processing information while experts have a top-down approach. Experts no longer perceive literally what they see, rather they interpret using their own experiences (Berlinger, 1988). Livingston and Borko (1989) believe that expert teachers are able to extract cues from the learning environment that enables them to have a deeper understanding of events and enables them to plan and teach to a greater level.

Behets (1996) studied experienced PE teachers’ observational abilities in teaching situations compared to that of preservice physical education teacher education students. Preservice teachers were either in their first or final year of their program. Participants were shown 12 slides depicting a gymnastics lesson and were asked to report what they detected 
within the slide, after a four second period of observation. Although no significant differences were reported between the three groups, differences were found between the number of critical events that were reported. Experienced teachers and final year students detected more critical events than that of first year PETE students. Behets (1996) contested that the perceptions of the participants at different stages of experience, their pedagogical content knowledge, not knowing where to look, or not recognizing the gymnasium situations in the same ways may have caused differences between participants.

Research completed by Graham et al. (1993) focused on two physical education teacher educators, seven juniors within a PETE program, and 10 students who were categorized as preservice. The focus of the study was to find difference between the three groups when they observed and interpreted the teaching and learning processes. The method utilized was to ask the participants to observe a physical education teacher instruct a third grade lesson. The participants were subsequently asked to describe what they observed via written description. Experts were able to describe what they observed in a much deeper and more descriptive fashion than the other two categories of participants. Specifically, experts tended to observe more of what happened in the lesson, organized their interpretation more, and their focus of evaluation was based more on student skill performance. Graham et al. (1993) proposed that the reasons for the differences were that novices could not draw upon their experiences which influenced their less developed schemata. It was also proposed that novices have not acquired the pedagogical content knowledge or pedagogical reasoning skills required to interpret what they observed.

Problem Representation and Solving. Experts have been found to take time to identify, define, and analyze a problem prior to seeking a solution, and may at times take longer than novices (Tan, 1997). Through a thorough analysis of a problem it allows the expert an 
opportunity to access previous patterns and their extensive knowledge base prior to implementing an adjustment or solution to a problem.

Even though the classroom is somewhat of a controlled environment classroom management and adjustments need to be made based on events that are occurring. The PE setting is of even greater complexity due to students being in a larger setting, the students are constantly moving which increases the risk of injury, and the equipment used is challenging (Behets, 1996). Housner and French (1994) found that, when compared to novices, experts were able to react quicker to the developing events within the classroom. Teachers must constantly interpret classroom events and make decisions based on these interpretations. These interpretations and adjustments are based on perceived inputs and past experiences of teachers (Behets, 1996). Further research completed by Manross and Templeton (1997) found that experts are able to make adjustments to their lessons at an early stage in order to prevent undesired outcomes and behaviors.

Effective problem solving in an efficient manner is a trait expert teachers are able to utilize, that novice teachers may struggle to address. Being able to recognize a problem when it arises and utilizing the pedagogical and classroom management skills needed to solve the problem is a skill set that is achieved over many years of experience. Swanson, O'Connor, and Cooney (1990) found that expert and novice teachers vary in regards to their solution and statements to cognitive processes relating to discipline problems within the classroom.

The extensive knowledge base and hierarchical organization of domain specific knowledge also helps the process of problem solving. Experts are able to readily access information due to their knowledge being stored logically and in usable forms that allows a number of solutions to various problems (McCullick et al., 2006). Defining what problem 
behavior is can be challenging yet the large experiential database of experts allows them to recognize problem behaviors even when aspects of their teaching may be somewhat automatic due to large levels of experience.

Automaticity of Behavior. As high levels of skill are developed, physically and mentally, an ability to perform in both an unconscious and automatic way arises (Tan, 1997). The automaticity of behavior provides opportunity for experts to focus on other aspects of their surroundings. Automaticity of behavior can only happen with a large amount of practice in similar situations. The large amount of experience required to allow this automaticity of behavior helps provide a strong argument for teacher education programs infused with early and frequent practicum experiences.

As teachers exit teacher education programs and begin as novice physical educators their experience begins to increase daily. Researchers observed $1^{\text {st }}$ year teachers and veteran teachers and they were compared in regards to completing school year goals. The results of this study indicate that veteran teachers met their start of the school year goals much easier than first year teachers (Siedentop \& Eldar, 1989). The ease with which the veteran teachers managed to meet their goals shows similarities between the concepts of automaticity that Bloom (1986) promoted.

Housner and Griffey (1985) found that experienced physical education teachers focused more on the performance of students than the novices. Student performance and achievement is an area which experienced physical educators are much more focused than novices. The notion of "busy, happy, good" is a concept that many novice physical educators focus on, as this reduces possible behavioral and management issues. To the novice educator it is important that children stay on task and do not provide problems for them to deal with. Experienced teachers have their management strategies and routines organized and laid out in advanced. Through 
comfort and experience regarding management the experienced teacher is able to focus on the student learning as opposed to management. Doyle (1986) believed the two primary purposes of a teacher are to promote learning and maintain order. Once classroom management becomes and automatic behavior for experienced teacher then student learning can be focused on.

Extensive Memory in Their Domain - Short and Long Term. Possessing an extensive memory within their domain helps experts build a knowledge base regarding teaching and learning (McCullick et al., 2006). Research indicates that having extensive memory is domain specific knowledge (Bruer, 1993). This domain specific knowledge allows a level of comfort for the expert individual when compared to the novice. The greater capacity for recalling information that is stored in short or long term memory arises from the way the information is stored in a strategically significant way (Tan, 1997). Allard and Burnett (1985) found that expert athletes, when compared to nonexpert athletes, were superior at reconstructing realistic and meaningful plays and tactical situations.

Experts are able to surpass the general limits of short term memory through the automaticity of their behavior (Tan, 1997). McCullick et al. (2006) found that the working memory of expert sport instructors demonstrated a pattern of rich understanding, was arranged in an organized manner, and included a skill analysis that was of a high quality. Expert teachers $(n=43)$ were shown a series of slides showing visual representations of gameplay and instructional situation in their domain. The protocol required the subjects to view a slide for five seconds then recall as much as possible from the slides. The oral responses were recorded, transcribed, and then analyzed. The analysis used Huberman and Miles’ (1995) four stage analysis to extract themes. The findings of McCullick and colleagues (2006) supports Ericsson’s (2003) notion that working memory is improved with practice and experience. The findings also 
provide evidence that working memory is a very important tool within pedagogy. Practicing and enhancing working memory could provide a possible area to help create and increase a level of teaching expertise (McCullick et al., 2006).

Self-Monitoring. Expert teachers are effective at observing problems and providing solutions to those problems. While problem solving of the individuals that they teach is an important part of their job, being an expert teacher and being able to self-monitor their own behavior and fix their own shortcomings is a vital part of expertise. Glaser et al. (1988) argued that the superior self-monitoring and self-knowledge that experts possess illustrates their larger domain specific knowledge. The authors also argue the variation of the representation of that knowledge separates experts from non-experts. If objective self-monitoring is possible then physical education teachers are able to grow as a professional. As experts objectively assess and identify their failings they are able to analyze the reasons for these failings and provide strategies to correct these issues (Tan, 1997).

O’Sullivan and Tsangaridou (1997) found that within physical education teaching day-today reflection adjusted physical education teachers’ practices on a daily basis adjusting issues relating to pedagogy, ethics, and social issues. The authors also found that reflection over time adjusts the teachers' methods within the classroom, and their professional development. The findings of O’Sullivan and Tsangaridou (1997) echo the belief of Berliner (2001) that in the selfregulatory stage of developing expertise the individual controls a great deal of their environment, conditions of deliberate practice are arranged and adjusted, feedback is received, and the level of challenge development is selected.

Standal and Moe (2013) completed a literature review attempting to find common themes within reflective practice in physical education teacher education. The review found that pre- 
service physical education teachers do develop reflective capabilities yet they struggle to make critical reflection of their self. Through experience, awareness via structured and reflective PETE program, and a greater domain specific knowledge base, expert teachers are able to objectively reflect on their shortcomings and attempt to problem solve ways to improve their teaching. The concept of self-monitoring is supported by the large knowledge base and the hierarchical format that experts store information are two reasons why experts are superior at self-monitoring (Tan, 1997).

\section{Coaching Expertise}

Physical education and sport have a large number of similarities (Drewe, 2000). The similarities between teaching and coaching can be clearly seen. Both teaching and coaching can provide a lasting impact on children. Depending upon the environment and level of coaching it is possible that coaches have a greater influence and impact upon the individuals they are in a position of authority over than a teacher. Recalling his previous experiences as both a coach and teacher Clack (2012) discussed the corrective measures used to motivate athletes and greater demands that coaches can place on individuals both physically and in terms of time constraints. Drewe (2000) examined the relationship between teaching and coaching and found that although both the job of a coach and a physical education teacher encompass the teaching of skills, strategies, and techniques, there is somewhat of a "coach not teacher" attitude which can hamper cooperation between disciplines.

As the field of coaching has progressed so has the role of coaches. The modern coach is required to provide technical and pedagogical skills, and has multitasking abilities (Salmela, 1996). The ever evolving role of a coach should be considered when researching coaching expertise as the requirements of expertise are changing as the job description alters. The body of 
research into coaching expertise is still emerging when compared to the previously mentioned disciplines.

Extensive Domain Specific Knowledge. As with both the general education and physical education disciplines coaching expertise requires extensive domain specific knowledge which may lead to expertise. Having an extensive knowledge base is an important characteristic for the individuals who become expert coaches (Drewe, 2000; Leas \& Chi, 1993; Schempp, McCullick \& Mason, 2006). An extensive knowledge base for coaches should include knowledge in sport sciences, sport specific knowledge, and pedagogical content knowledge (Abraham et al., 2006). An extensive knowledge base should lay the foundation to achieve coaching expertise.

According to Cote and Gilbert (2009) the Abraham et al. (2006) areas of knowledge provides the "how to" of coaching knowledge that has been promoted as enabling people to become promoted as experts via accumulating this professional knowledge. Although many coaches may have large domain specific knowledge bases it does not automatically result in achieving expertise of being an effective coach (Becker, 2009; Cassidy et al., 2009). The extensive domain specific knowledge base of expert coaches encompasses a large number of items including sport specific knowledge, management of team and players, and skills in planning and coaching (DeMarco \& McCullick, 1997). As with all domains of teaching or coaching it is not merely a case of memorize and recite declarative knowledge.

Hierarchical Organization of Knowledge. Although there is no all-encompassing definition of "knowledge" there is a concept of including both declarative and procedural knowledge (Cote \& Gilbert, 2009). Knowledge within pedagogical concepts relating to the coach’s specific sport is extremely similar to that of physical education teachers teaching a unit 
on a specific sport. The structure of knowledge and components required to be an expert coach are very diverse. Several variables are used by expert coaches to provide successful and meaning opportunities for athletes. Expert coaches must have a great deal of organizational work and should have large knowledge bases in technical and tactical areas, and also knowledge in psychosocial aspects along with organizational areas (Vieira, Dias, Corte-Real \& Fonseca, 2014).

The knowledge structures of coaches are very complex (Jones, Armour \& Potrac, 2003; Salmela, Russell, Cote \& Baria, 1994). The knowledge base is created over many years of practice and performance at varying levels of competition and practice (Coyle, 2009). Being able to access the information quickly and efficiently to adjust to a variety of situations is an important skill for an expert coach to possess. Salmela et al. (1994) found that coaches’ had interconnected knowledge sets that include procedural, declarative, and metacognitive knowledge.

Cote, Salmela, Trudel, Baria, and Russell (1995) studied the cognitive structures of 17 top-level gymnastic coaches. Coaches were selected based on multiple criteria including a minimum of 10 years coaching experience, experience coaching at a high level of competition, experience coaching national or international level gymnasts, and were recognized by their national federation for developing elite level gymnasts. The process of knowledge elicitation used open ended and other questioning methods. Cote et al. (1995) provided an unstructured interview to expert coaches following the proposal of Marshall and Rossman (1989) that elite performers or experts are able to respond in a more in-depth manner via interviews that allows them to use their knowledge. The results of the analysis consisted of arranging components into categories that experts focus on and can be transferred into a model. The components were found 
to be are competition, training, organization, coach's characteristics, athlete’s characteristics, and contextual factors. Tan (1997) argued the knowledge of experts is structured in an intricate format that allows ease of access of information that needs to be recalled and applied.

Acute Perceptual Capacities. Expert coaches must use their large domain specific knowledge base and hierarchical organization of that knowledge to inform their practices. A coach is expected to regularly critique, adjust, and improve an athlete's individual or a team's performance. Experts are able to recognize performance patterns and details that individuals without expertise would miss or dismiss (Tan, 1997). Schempp et al. (2006) found that expert coaches are aided through their perceptual skills. The perceptual skills of expert coaches aid in several ways including: predicting outcomes faster than nonexperts would, addressing athlete performance in a game setting, supplying content to improve athletes, and recognition of influences that impact individual athletes or the team.

The perceptual capacities of four expert and four novice tennis instructors were studied by Woorons (2001). The participants used both a video analysis and a recall test. Participants were asked to describe what they observed in a 10 minute instructional video. The recall test involved 10 slides related to tennis with both groups of participants asked to recall everything they could. Woorons (2001) found that there were differences between experts and novices in regards to instruction and motor skill analysis yet no difference in the quantity of cues detected. Although there was no difference in the quantity of cues detected there was a significant difference between what experts and novices saw. Novice coaches within the study had observations that were quite superficial ranging from clothing to location of cars in the parking lot. Experts tended to focus on factors that altered performance assessment and the necessary 
steps to improve this. Experts were also found to be more methodical and critical than novice instructors.

Research by Jones, Housner, and Kornspan (1997) studied coaches’ behavior and their interactive decision making. The participants of the study were 10 experienced and 10 inexperienced coaches. The coaches delivered a 30 minute practice session on the "give and go" in basketball having had 30 minutes to plan the practice. The results of the study demonstrated that experienced coaches’ demonstrated significantly more technical skill instruction and inexperienced coaches provided more silent observation. According to the authors this may indicate that inexperienced coaches were unable to diagnose skill performance errors and provide meaningful feedback.

Leas and Chi (1993) studied the diagnostic knowledge of expert and novice swimming coaches. A comparison between the experts and novices found that expert coaches provided a greater knowledge base when describing a technique, provided a more well-rounded diagnosis, and were more accurate than novices. The ability to recognize patterns in performance based on a strong knowledge base allows experts to quickly extract meaningful chunks of information from a situation which may seem extremely complicated and challenging to a novice (Tan, 1997). Once an expert has recognized a pattern in performance or an issue with performance via their acute perceptual capacities, having utilized their extensive domain specific knowledge base and hierarchical structure of knowledge, they must then problem solve.

Problem Representation and Solving. When a coach observes a behavior or cue that is recognized as problematic they must find a way to make adjustments to solve the problem. Expert coaches are able to accurately, quickly, and efficiently solve problems (Schempp et al., 2006). Jones et al. (1997) proved that differences between expert and novice coaches exist in 
relation to problem situations. Expert coaches were found to make no changes to perceived problem situations unless they were deemed to be serious safety problems.

Vergeer and Lyle (2009) investigated the influence of situational factors on the decisions made by coaches and the ways they rationalize and deliberate to make their decisions. The participants were 64 registered coaches of female competitive gymnasts. The coaches completed a telephone survey where 16 hypothetical scenarios were provided to the participant and four situation parameters were provided. Once the coaches had been provided with the scenario they were encouraged to take notes prior to providing a response as to how they would respond in that scenario. The coaches then rated the likelihood of the athlete participating in each of the scenarios they were provided on a 10 point scale. They were then asked to provide comments on the reasons and considerations that helped their decision. It was found that coaches with more experience included more managerial aspects within the judgment making process when compared to coaches with less experience. Less experienced coaches were found to characterize problems in a more superficial way.

Research in both teaching and coaching has provided some further insight into the problem solving of expert teachers and coaches. Within education Berliner (1994) and within coaching Schempp et al. (2006) found that experts can use intuition relating to the situation to problem solve and make decisions. Through prolonged experimentation, reflective practical coaching, success, and failures experts achieve a level of intuitive ability (Schempp et al. 2006). The decision making and problem solving of expert coaches are based on the coaches' feeling of what they believe needs to happen, although this may defy conventional reasoning (Schempp et al., 2012). Although succinctly defining what a problem is may be challenging the large experiential database and experience of experts allows recognition of problem behaviors or cues 
that they will have to solve. Problem solving is possible even when aspects of their coaching may be somewhat automatic due to large levels of experience.

Automaticity of Behavior. Experts are able to do complex processes automatically as opposed to nonexperts who can only do complex tasks with much effort (Bloom, 1986). Through years of experience and environment familiarity experts can repeat and rehearse their patterns of behavior that allows a seemingly automatic routine and behavior to be displayed (Tan, 1997). The ability to accurately complete tasks in a quick and accurate manner while providing small levels of cognitive guidance is a trait experts possess (Schempp et al., 2012).

Having extensive experience, a large domain specific knowledge base and practical knowledge enables an expert coach to execute several essential coaching traits with automaticity including: practice openings, equipment organization, communication, explanations, player movement, examples, management, and activities (Bloom, 1986; Schempp et al., 2006). Through automaticity of behavior and skill demonstration, in a way that seems unconscious, allows memory resources to be open for the storage of a variety of new resources and information within both the long term and short term memory (Tan, 1997)

Extensive Memory in Their Domain - Short and Long Term. Automaticity of behavior allows experts to exceed the general limitations of short term memory (Tan, 1997). An extensive memory, in both the short term and long term forms, can be a vital tool for expert coaches as this can aid and guide their professional practice. Expert coaches are able to recall small details regarding the recent past along with details from their long term experience (Tan, 1997). Woorons (2001) believed that an explanation for experts' exceptional memory particularly their short term, when compared to novices', is the automaticity of behavior. 
As previously mentioned McCullick et al. (2006) studied 43 expert teachers to evaluate the working memory of expert sport instructors. In this study sport instructor was a term used synonymously with coach. The participants were shown a series of slides which depicted instructional episodes and game play within their domain. The slides were viewed for five seconds and then the participants were asked to recall as much as possible. Themes and commonalities were elicited from the audio responses of the participants via the Huberman and Miles (1995) four-stage analysis framework. Expert sports instructors’ working memories were found to be deep and rich, were hierarchically ordered, and included thorough skill analysis. The findings of the aforementioned study support Ericsson’s (2003) work that promotes working memory as not merely a genetic or natural trait and that through experience and practice working memory can be learned and improved. The opportunity to increase working memory via experience and practice is one method a characteristic of expertise can be increased. Expert instructors’ working memory, and improvement of this, is a pedagogical tool which can be practiced and improved in order to increase expertise (McCullick et al., 2006).

Self-Monitoring. Experts are able to precisely, objectively and honestly pinpoint their failings and deficiencies within their knowledge base (Tan, 1997). Experts’ high level of selfmonitoring skills and self-knowledge is due to their extensive knowledge base and the method in which their memory stores that information (Tan, 1997). As previously mentioned the extensive knowledge base of expert's is gained via years of experience. When related to experts, particularly coaching and sport instruction, self-monitoring can be described as skills and knowledge that experts scrutinize in order to improve their effectiveness (Schempp et al., 2006). Schempp et al. (2006) collected data from 31 expert golf teachers asking the teachers to list the aspects of their teaching which they monitored on a regular basis when assessing their 
own strengths and weaknesses. The data collected was analyzed in three steps. The steps were identifying the characteristics monitored, grouping themes, and unanimous agreement by investigators. It was found that preceding or following an instructional episode experts were duteous in their self-assessment of skills, knowledge base, personal traits, and philosophy. In a further study of expert golf coaches they were found to self-monitor several traits in an attempt to devise goals to improve their teaching effectiveness including communication, perspective, actions, learning, and lifestyle (Schempp et al., 2006).

The extensive self-assessment process completed by expert coaches allows a greater selfunderstanding. Due to their ability to assess shortcomings, experts are able to take corrective action (Tan, 1997). Once expert coaches have assessed themselves they are then able to devise a strategy in order to improve their future performances along with methods to continually evaluate their performance (Schempp et al., 2012). Through self-monitoring expert coaches are able to further use their findings for knowledge acquisition which allows them to make strategic plans to improve their deficiencies (Schempp et al., 2012).

Self-monitoring is believed to be a feature of professionalism as the process effects important aspects of an occupation (Kilbourn, 1991). Through self-monitoring this allows a teacher or coach to evolve past the evaluation phase of their experience and progress to a intrinsic process of unbiased self-analysis (Karoly, 1993). Ensuring coaches at all stages of expertise engage in self-monitoring is an integral part of a coach’s development (Schempp et al., 2012).

\section{Summary}

Developing coaching expertise is a prolonged process that requires education, experience, and practice of essential skills (Schempp et al. 2012). Research in the field of coaching expertise 
has provided three consistent areas that allow expertise to be measured and these are experience, knowledge, and skills (Schempp \& McCullick, 2010). Schempp et al. (2012) believe the greater level of experience, skills, and knowledge an individual possess the greater their ability to coach. Tan (1997) promotes that the body of research compiled regarding the elements of expertise provides the educational and sporting communities insight into expertise within teaching and coaching. Understanding that experts possess unique characteristics that allow their differentiation from novices and competent individuals do not necessarily allow an easy method of transferring these characteristics to aid the development of expertise.

Not all individuals have the desire, opportunity, or ability to reach a level of expertise but through identifying and developing characteristics of expertise teachers and coaches can develop more expertise within their domain (Tan, 1997). Woorons (2001) believed that the perceptual capacities she studied may be linked closely to the other characteristics mentioned by Tan (1997) such as extensive domain specific knowledge base, hierarchical organization of knowledge, problem representation and solving, automaticity of behavior, long and short term memory, and self-monitoring. Woorons (2001) also calls for additional studies that offer empirical evidence of the association between perceptual capacities and the aforementioned experts' characteristics.

Although experience is important in reaching expertise and the idea of 10 years of preparation (Tan, 1997) or 10,000 and 20,000 hours (Chase \& Simon, 1973) have been promoted experience does not automatically result in being an expert coach or even a competent coach (Schempp et al., 2012). A large body of research has been completed seeking similarities and difference between expert and novice coaches or sport instructors (Jones et al., 1995; Jones et al., 1997; McCullick et al., 2006; Schempp et al., 2006; Siedentop \& Eldar, 1989; Tan, 1997; Woorons, 2001). A smaller body of research has been compiled that analyzes the similarities and 
differences between coaches who are progressing along the continuum from novice or beginner towards expertise (Vergeer \& Lyle, 2009; Vickers \& Wax, 2012). As previously mentioned experience does not equate to expertise and is merely a component. Cushion et al. (2003) indicated that a limited body or research has been compiled that focuses on coaching practices and the influence of experience on this. Vickers and Wax (2012) echoed the sentiments of Cushion et al. (2003) when they promoted the importance of future studies in coaching education that investigate coaches with identifiable and varying levels of experience. 


\section{References}

Abraham, A., Collins, D., \& Martindale, R. (2006). The coaching schematic: Validation through expert coach consensus. Journal of Sports Sciences, 24, 549-564.

Addams, J. (1990). Twenty Years at Hull House, with Autobiographical Notes. Champaign, Ill: Project Gutenberg.

Allard, F., \& Burnett, N. (1985). Skill in sport. Canadian Journal of Psychology, 39(2), 294-312.

Armour, K., \& Yelling, M. (2004). Professional development and professional learning: Bridging the gap for experienced physical education teachers. European Physical Education Review, 10, 71-93.

Becker, A.J. (2009). It's not what they do, it's how they do it: Athlete experiences of great coaching. International Journal of Sports Science and Coaching, 4, 93-119.

Behets, D. (1996). Comparison of visual information processing between preservice students and experienced physical education teachers. Journal of Teaching in Physical Education, 16, 79-87.

Berliner, D.C. (1986). In pursuit of the expert pedagogue. Educational Researcher, 15 (7), 5-13.

Berliner, D.C. (1988). Implications of studies of expertise in pedagogy for teacher education and evaluation. New directions for teacher assessment: 1988 ETS Invitational Conference. Princeton, NJ.

Berliner, D. C. (1994). Expertise: The wonder of exemplary performances. Creating powerful thinking in teachers and students, 161-186. Ft. Worth, TX: Holt, Rinehart, \& Winston.

Berliner, D. C. (2001). Learning about and learning from expert teachers. International Journal of Educational Research, 35(5), 463-482. 
Bloom, B. S. (1986). Automaticity: "The Hands and Feet of Genius". Educational leadership, 43(5), 70-77.

Borko, H. (2004). Professional development and teacher learning: Mapping the terrain. Educational Researcher, 33(8), 3-15.

Bruer, J.T. (1993). The mind's journey from novice to expert: If we know the route, we can help students negotiate their way. American Educator: The Professional Journal of the American Federation of Teachers, 17 (2), 6-46.

Carter, K., Cushing, K., Sabers, D., Stein, P., \& Berliner, D., (1988). Expert-novice differences in perceiving and processing visual classroom information. Journal of Teacher Education, 39(3), 25-31.

Cassidy, T.G., Jones, R.L., \& Potrac, P. (2009). Understanding sports coaching: The social, cultural and pedagogical foundations of coaching practice. London: Routledge.

Chase, W.G., \& Simon, H.A. (1973). Perception in chess. Cognitive psychology, 4(1), 55-81.

Chen, W., \& Rovegno, I. (2000). Examination of expert and novice teachers' constructivistoriented teaching practices using a movement approach to elementary physical education. Research Quarterly for Exercise and Sport, 71(4), 357-372.

Chi, M.T.H., Feltovich, P.J., \& Glaser, R. (1981). Categorization and representation of physics problems by experts and novices. Cognitive Science, 5(2), 121-152.

Chi, M.T.H., Glaser R., \& Rees, E. (1982). Expertise in problem solving. In R.S. Sternberg (Ed.), Advances in the Psychology of Human Intelligence (pp. 1-75). Hillsdale, NJ: Erlbaum. Clack, J. (2012, December). Teaching and Coaching. Bioscene: Journal of College Biology Teaching, 37(2), 48-49. 
Claridge, P.B. (1988). Alternative perspectives for analyzing expert, novice, and postulant teaching (Unpublished doctoral dissertation). University of Arizona, Tucson, AZ.

Côté, J. \& Gilbert, W. (2009). An integrative definition of coaching effectiveness and expertise. International Journal of Sports Science and Coaching, 4(3), 307-323.

Cote, J., Salmela, J.H., Trudel, P., Baria, A., \& Russell, S. (1995). The coaching model: A grounded assessment of expert gymnastic coaches' knowledge. Journal of Sport and Exercise Psychology, 17(1), 1-17.

Coyle, D. (2009). The talent code: Greatness isn't born. It's Grown. Here’s How. New York City, NY: Bantam.

Cushion, C.J., Armour, K.M., \& Jones, R.L. (2003). Coach education and continuing professional development: Experience and learning to coach. Quest, 55(3), 215-230.

De Grave, W.S., Boshuizen, H.P.A., \& Schmidt, H.G. (1996). Problem based learning: Cognitive and metacognitive processes during problem analysis. Instructional science, 24(5), 321341.

De Groot, A. (1978). Thought and choice in chess. Berlin: Mouton De Gruyter.

De Marco Jr, G.M., \& McCullick, B.A. (1997). Developing expertise in coaching: Learning from the legends. Journal of Physical Education, Recreation \& Dance, 68(3), 37-41.

Doyle, W. (1986). Classroom organization and management. In M.C. Wittrock (Ed.), Handbook of research on teaching (3rd ed., pp. 392-431). New York: Macmillan.

Drewe, S.B. (2000). An examination of the relationship between coaching and teaching. Quest, 52(1), 79-88.

Ericsson, K.A. (2003). Development of elite performance and deliberate practice: An update from the perspective of the expert performance approach. In J.L. Starkes \& K.A. Ericsson 
(Eds.), Expert performance in sports: Advances in research on sport expertise (pp.4983). Champaign, IL: Human Kinetics.

Ericsson, K.A. (2006). An introduction to the Cambridge handbook of expertise and expert performance: Its development, organization, and content. In K.A. Ericsson, N. Charness, P.J., Feltovich, \& R.R. Hoffman (Eds.). The Cambridge handbook of expertise and expert performance (pp. 3-19). New York: Cambridge University Press.

Ericsson, K.A., \& Charness, N. (1994). Expert performance: Its structure and acquisition. American psychologist, 49(8), 725.

Ericsson, K.A., Krampe, R.T., \& Tesch-Römer, C. (1993). The role of deliberate practice in the acquisition of expert performance. Psychological Review, 100(3), 363.

Ericsson, K. A., \& Smith, J. (Eds.). (1991). Toward a general theory of expertise: Prospects and limits. New York: Cambridge University Press.

Everhart, B., Everhart, K., McHugh, H., Newman, C.D., Hershey, K., \& Lorenzi, D. (2013). Teaching-learning patterns of expert and novice adapted physical educators. Education, 133(4), 456-469.

Glaser, R., Chi, M.T., \& Farr, M.J. (Eds.). (1988). The nature of expertise (pp. xv-xxviii). Hillsdale, NJ: Lawrence Erlbaum Associates.

Graham, K.C., French, K.E., \& Woods, A.M. (1993). Observing and interpreting teachinglearning processes: Novice PETE students, experienced PETE students, and expert teacher educators. Journal of Teaching in Physical Education, 13, 46-46.

Griffey, D., \& Housner, L. (1991). Differences between experienced and inexperienced teachers' planning decisions, interactions, student engagement, and instructional climate. Research Quarterly for Exercise and Sport, 62, 196-204. 
Hansen, D.T. (2008). Why educate teachers? In M. Cochran-Smith, S. Feiman-Nemser, D.J. Mclntyre, \& K.I.E. Demers (Eds.), Handbook of research on teacher education: Enduring questions in changing contexts (3rd ed., pp. 5-9). New York: Routledge, Taylor, \& Francis.

Housner, L. D., \& French, K. E. (1994). Future directions for research on expertise in learning, performance, and instruction in sport and physical activity. Quest, 46(2), 241-246.

Housner, L D., \& Griffey, D C (1985) Teacher cognition. Differences in planning and interactive decision-making between experienced and inexperienced teachers. Research Quarterly for Exercise and Sport, 56, 45-53.

Huber, J. (1997). Differences in problem representation and procedural knowledge between elite and nonelite springboard divers. The Sport Psychologist, 11, 142-159.

Huberman, A.M., \& Miles, M.B. (1995). Data management and analysis methods. In N.K. Denzin \& Y.S. Lincoln (Eds.), Handbook of qualitative research (pp. 428-444). Thousand Oaks, CA: Sage.

Jones, R. L., Armour, K. M., \& Potrac, P. (2003). Constructing expert knowledge: A case study of a top-level professional soccer coach. Sport, Education \& Society, 8(2), 213.

Jones, D., Housner, L., \& Kornspan, A. (1997). Interactive decision making and behavior of experienced and inexperienced basketball coaches during practice. Journal of Teaching in Physical Education, 16(4), 454-468.

Karoly, P. (1993). Mechanisms of self-regulation: A systems view. Annual review of psychology, 44(1), 23-52.

Kilbourn, B. (1991). Self-monitoring in teaching. American Educational Research Journal, 28(4), 721-736. 
Kim, I. (2012). Content knowledge, pedagogical content knowledge, and student learning. Research Quarterly for Exercise and Sport, 83, A-3.

Leas, R.R., \& Chi, M.T. (1993). Analyzing diagnostic expertise of competitive swimming coaches. Advances in psychology, 102, 75-94.

Lee, Y. S. (2012, March). The effects of a content knowledge workshop in physical education. Research Quarterly for Exercise and Sport, 83, A-2.

Leinhardt, G., \& Greeno, J. L. (1986). The cognitive skill of teaching. Journal of Educational Psychology, 77, 247-271.

Livingston, C. \& Borko, H. (1989). Expert-novice differences in teaching: A cognitive analysis and implications for teacher education. Journal of teacher education, 40(4), 36-42.

Manross, D., \& Templeton, C. L. (1997). Expertise in teaching physical education. Journal of Physical Education, Recreation \& Dance, 68(3), 29-35

Marshall, C, \& Rossman, G.B. (1989). Designing qualitative research. Newbury Park, CA: Sage.

McCullick B., Schempp P., Hsu S., Jung J., Vickers B., Schuknecht G. (2006). An analysis of the working memories of expert sport instructors. Journal of Teaching in Physical Education, 25(2), 149-165.

Nelson, K.R. (1988). Thinking processes, management routines and student perceptions of expert and novice physical education teachers (Unpublished doctoral dissertation). Louisiana State University, Baton Rouge, LA.

O’Sullivan, M., \& Tsangaridou, N. (1997). The role of reflection in shaping physical education teacher, educational values and practices. Journal of Teaching in Physical Education, 17(1), 2-25. 
Peterson, P.L., \& Comeaux, M.A. (1987). Teachers' schemata for classroom events. The mental scaffolding of teachers' thinking during classroom instruction. Teaching and Teacher Education, 3, 319-331.

Rink, J. E., French, K., Lee, A. M., Solmon, M. A., \& Lynn, S. K. (1994). A comparison of pedagogical knowledge structures of preservice students and teacher educators in two institutions. Journal of Teaching in Physical Education, 13(2), 140-162.

Rink, J.E. (2003). Effective instruction in physical education. In S.J. Silverman and C.D. Ennis (Eds.), Student Learning in Physical Education: Applying Research to Enhance Instruction. Champaign, IL: Human Kinetics.

Sabers, D. S., Cushing, K. S., \& Berliner, D. C. (1991). Differences among teachers in a task characterized by simultaneity, multidimensional, and immediacy. American Educational Research Journal, 28(1), 63-88.

Salmela, J.H.. (1996) Great job coach! Getting the edge from proven winners. Ottawa, ON: Potentium.

Salmela, J. H., Russell, S. J., Côté, J. \& Baria, A. (1994). The structure of expert knowledge in coaches. Advances in Sport Psychology, 2, 56-65.

Schempp, P. G., McCullick, B. A., Busch, C. A., Webster, C., \& Mason, I. S. (2006). The selfmonitoring of expert sport instructors. International Journal of Sports Science and Coaching, 1(1), 25-35.

Schempp, P. G., McCullick, B. A., \& Grant, M. A. (2012). Teaching coaching expertise: How to educate for coaching excellence. In J.O. Dea (ed.) Current Issues and Controversies in School and Community Health, Sport, and Physical Education. Hauppauge, NY: Nova Science Publishers, 251-263. 
Schempp, P. G., \& McCullick, B. (2010). Coaches’ expertise. In J. Lyle \& C. Cushion (Eds.), Sports Coaching: Professionalization and Practice (221-231). Amsterdam: Elsevier.

Schempp, P., McCullick, B., \& Mason, I. (2006). The development of expert coaching. The sports coach as educator: Reconceptualizing sports coaching. London: Routledge.

Shulman, L.S. (1987). Knowledge and teaching: Foundations of the new reform. Harvard Educational Review, 57 (1), 1-22.

Siedentop, D., \& Eldar, E. (1989). Expertise, experience, and effectiveness. Journal of Teaching in Physical Education, 8, 254-260.

Soloway, E., Adelson, Bl., \& Ehrlich, K. (1988). Knowledge and processes in the comprehension computer programs. In M.T.H. Chi, R. Glaser, \& M. J. Farr (Eds.) The Nature of Expertise (pp. 129-159). Hillsdale, NJ: Lawrence Erlbaum Associates.

Standal, Ø. F., \& Moe, V. F. (2013). Reflective practice in physical education and physical education teacher education: A review of the literature since 1995. Quest, 65(2), 220-240.

Stein, P. \& Berliner, D.C. (April 1988) Expert, novice, and postulant teachers' thoughts during teaching. Paper presented at the meeting of the American Educational Research Association. New Orleans, LA.

Swanson, H., O'Connor, J. E., \& Cooney, J. B. (1990). An information processing analysis of expert and novice teachers' problem solving. American Educational Research Journal, 27(3), 533-556.

Tan, S. K. (1997). The elements of expertise. Journal of Physical Education, Recreation, and Dance, 68(2), 30-33.

Tricot, A., \& Sweller, J. (2014). Domain-specific knowledge and why teaching generic skills does not work. Educational Psychology Review, 26(2), 265-283. 
Vergeer, I., \& Lyle, J. (2009). Coaching experience: Examining its role in coaches’ decision making. International Journal of Sport and Exercise Psychology, 7(4), 431-449.

Vickers, B. \& Wax, B. (2012). Modes of learning utilized by coaches to increase knowledge and understanding. Sport Science Review, 21(5), 97-111.

Vieira, A.L., Dias, C.S.L., Corte-Real, N.J., \& Fonseca, A.M. (2014). The organization of the sport process: The perspective of elite volleyball Brazilian coaches. Pamukkale Journal of Sport Sciences, 5(1), 1-32.

Wood, D. (2007). Professional learning communities: Teachers, knowledge, and knowing. Theory into Practice, 46(4), 281-290.

Woorons, S.I. (2001). An analysis of expert and novice tennis instructors' perceptual capacities. (Unpublished doctoral dissertation). University of Georgia, Athens, GA.

You, J. (2011). Portraying physical education-pedagogical content knowledge for the professional learning of physical educators. Physical Educator, 68(2), 98-112. 